\title{
The Performance of the 1990s Canadian Labour Market
}

\author{
by Garnett Picot* and Andrew Heisz**
}

No. 148

\author{
11F0019MPE No. 148 \\ ISSN: 1200-5223 \\ ISBN: 0-662-28919-6
}

Price: $\$ 5.00$ per issue, $\$ 25.00$ annually

Business and Labour Market Analysis Division

24-F, R.H. Coats Building, Ottawa, K1A 0T6

*Statistics Canada (613) 951-8214

**Statistics Canada (613) 951-3748

Facsimile Number: (613) 951-5403

The paper is available on Internet: (www.statcan.ca)

\section{April 2000}

This paper represents the views of the authors and does not necessarily reflect the opinions of Statistics Canada. 


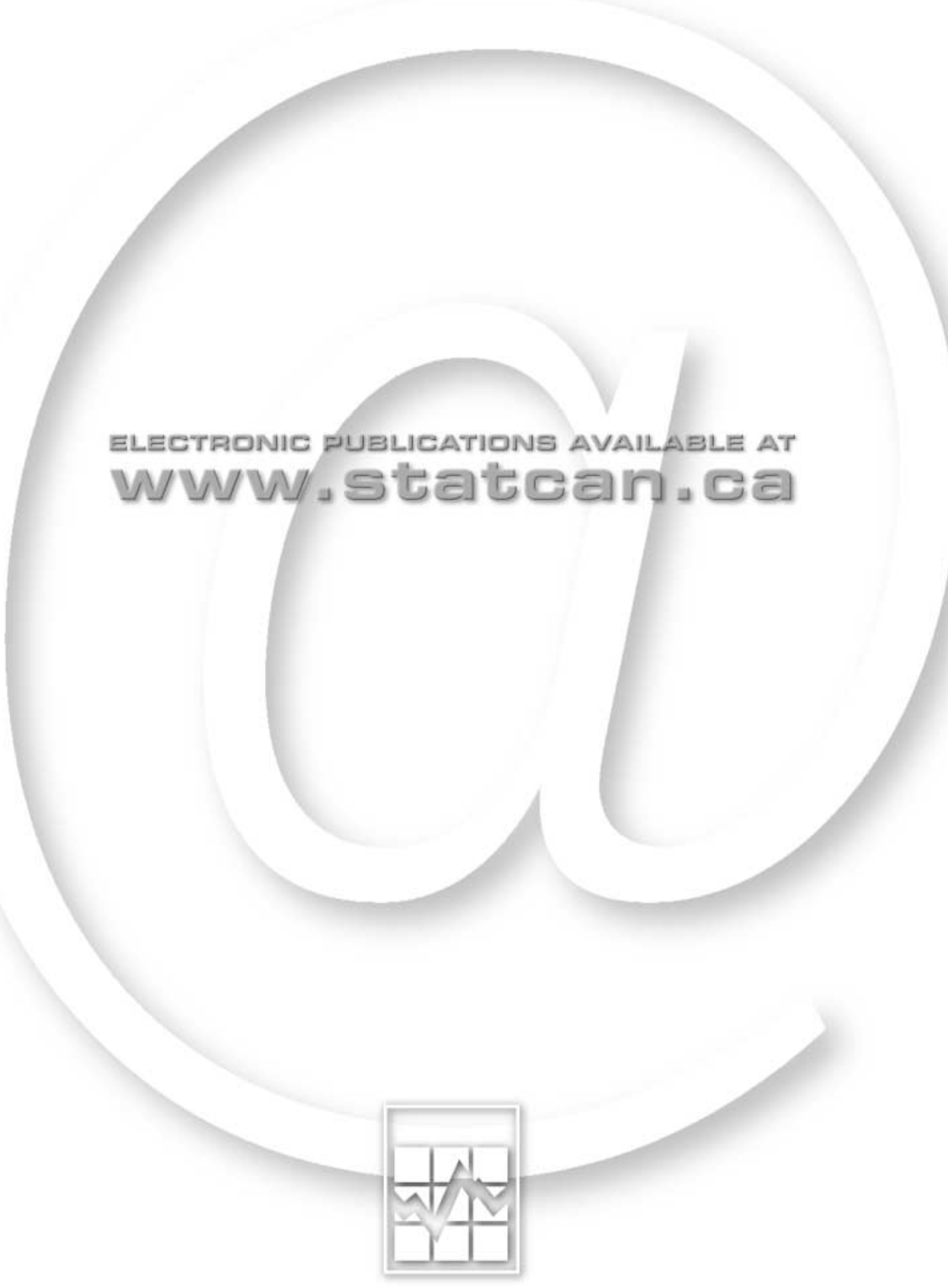




\section{Table of Contents}

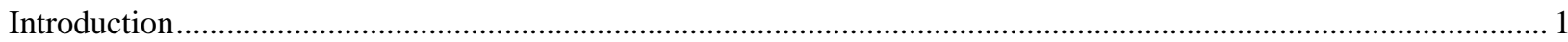

Why Would the 1990s Labour Market Have Deviated from the 1980s? ..................................................... 2

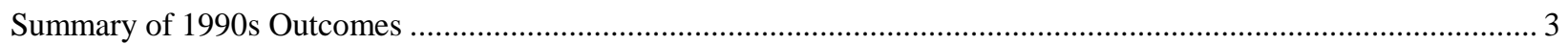

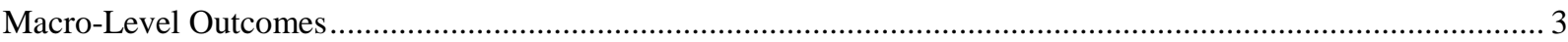

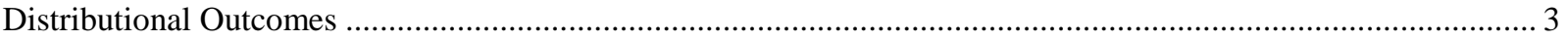

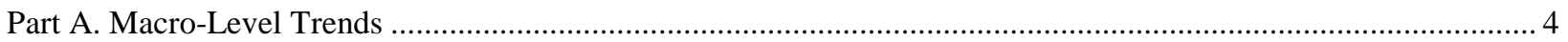

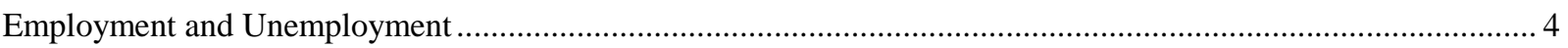

Does the Rise in Self-Employment Suggest a Fundamental Shift in the Nature of Work? ................................

Labour Force Participation and the Incidence and Duration of Unemployment ............................................ 7

The Decline in Labour Market Outcomes for Workers with a Given Level of Human Capital ..........................8

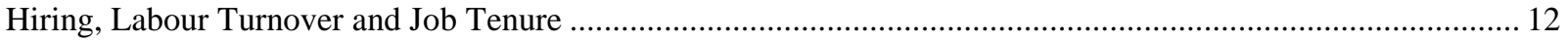

Do Trends in Aggregate Job Stability, Hiring and Labour Mobility Suggest Fundamental Change in the Nature of Work?

Job Creation and Destruction 14

Does the Evidence on Job Destruction and Downsizing Suggest Enduring Change in the Way Firms Manage their Workforces?.

If Productivity Increased at the Same Rate During the 1990s as 1980 s, Why the Slowdown in Income?

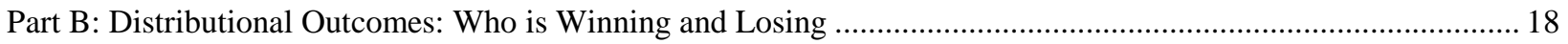

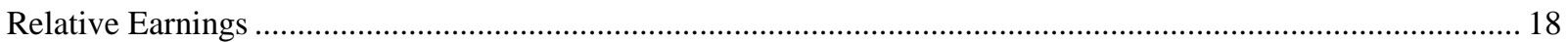

Declining Real Earnings Among Young Workers, Particularly Males ................................................... 18

The Labour Market Experiences of Recent Immigrants Resemble Those of Young Labour Force Entrants ...... 19

Relative Earnings of the More Highly Educated .......................................................................... 20

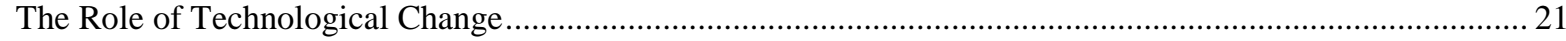

The Shifting Relative Labour Market Position of Men and Women ............................................................. 21

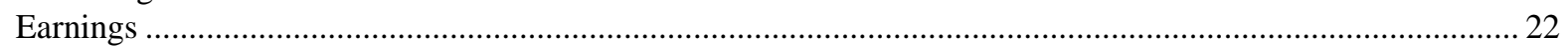

Employment Indicators Among Prime Aged Men and Women ................................................................. 24

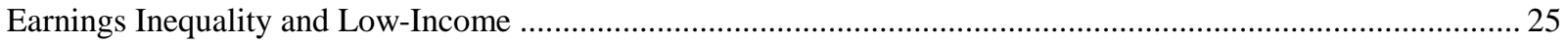

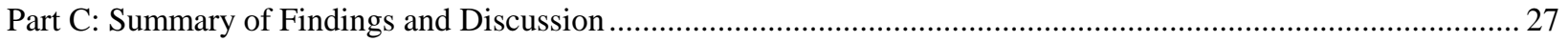

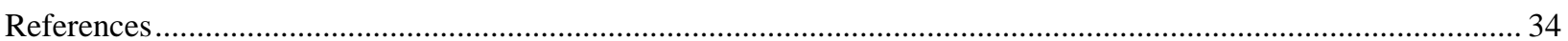




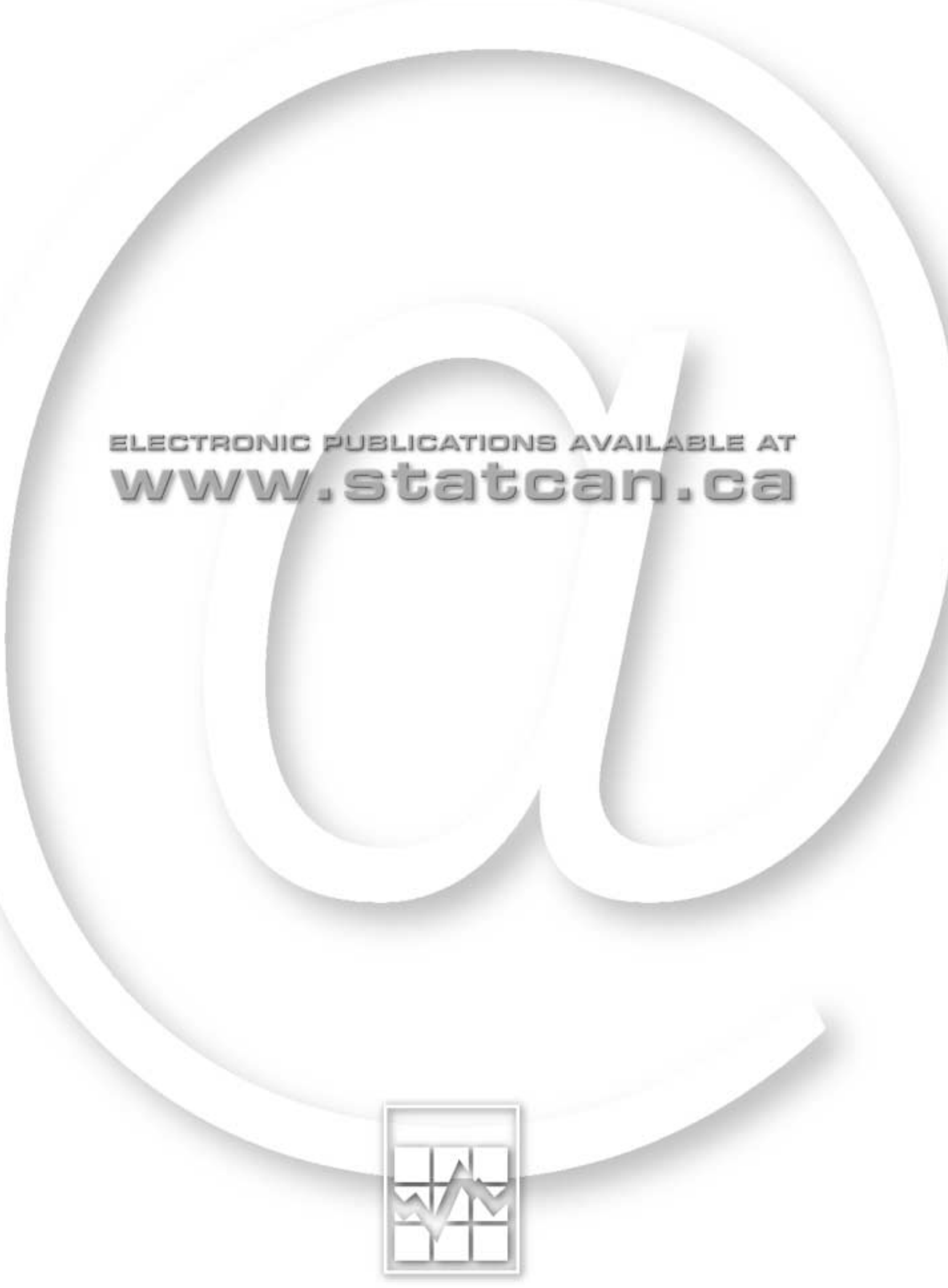




\section{ABSTRACT}

There is a general sense that the 1990s labour market was unique. It has been characterized by notions such as "downsizing", "technological revolution", "the knowledge-based economy", "rising job instability", and so on. This paper provides an extensive overview of the performance of the 1990s labour market, and asks just how different it was from the 1980s. It goes on to ask if the facts are consistent with many common beliefs and explanations. The paper focuses on (a) macro-level labour market outcomes, and (b) distributional outcomes. Macro-level topics include:

- Has the nature of work changed dramatically in the 1990s?

- Has there been a continued ratcheting up of unemployment?

- Have we witnessed rising job instability and increased levels of layoffs?

- Did company downsizing increase in the 1990s?

- Why did per capita income growth stall in the 1990s?

- For a worker with a given level of human capital, has there been a deterioration in labour market outcomes?

Much of the focus in the labour market over the 1980s and 1990s was on distributional outcomes...who is winning and who is losing. Some of the distributional outcomes of the 1990s labour market addressed in the paper include:

- Outcomes for men and women.

- Changes in the relative wages of the highly educated and earnings inequality.

- Trends in the rate of low-income.

- The changing outcomes for recent labour market entrants, including young people and immigrants.

- The extent to which technological change plays a major role in these outcomes.

The paper concludes with a discussion of the overall performance of the 1990s labour market as compared to the 1980s.

Keywords: Labour market, earnings, unemployment, inequality. 


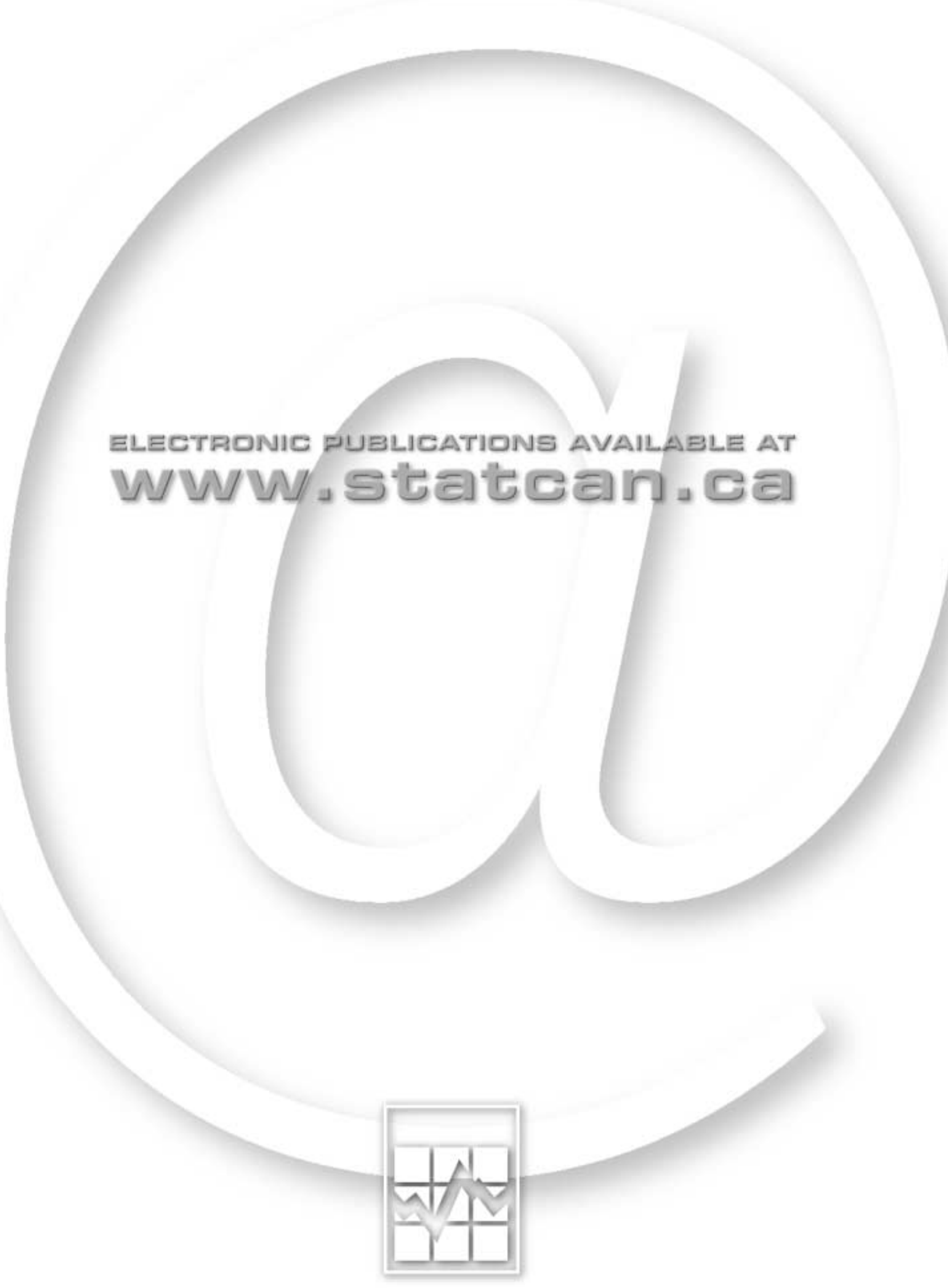




\section{Introduction}

The economy of the 1990s has been characterized by buzz-words and phrases such as "downsizing", "high performance workplaces", "increasing globalization", "technological revolution", "the end of work", and "the knowledge-based economy". The notion behind most of these phrases is that competitive and technological pressures have radically altered the production processes, hiring, and business strategies of firms in such a way so as to affect the labour market in a major and often negative manner. Some of the outcomes seen to be associated with this change include:

- Downsizing and job destruction, which stem from the need to reduce costs and the increased use of technology

- Firms seeking productivity growth by changing the way they engage labour and increasing the use of technology (particularly computers)

- A fundamental change in the nature of work, as firms turn to contracting-out and contingent labour in the face of rising competition

- Rising relative demand for the more highly skilled and educated, in the face of the shift to the "knowledge-based" economy

- Rising job instability, as firms manage their workforces in a fundamentally different way

- Rising earnings inequality, driven by technological change.

However, in addition to change resulting from the impact of technology and competition on labour demand, there are other factors that potentially affected outcomes in the 1990s, including: 1) a weak economic recovery, 2) supply-side shifts, 3) changing labour market institutions, and

4) change in the way firms organize their workforces. Much is unknown regarding the effect of each of these dimensions during the past decade. This paper will contrast the major labour market events of the 1990s cycle (to date) with those of the 1980s. The first goal is to better understand how the 1990s market deviated from the 1980s. In particular, the focus is on the outcomes listed above. Did these events occur, and did they occur in a way consistent with the notions described? However, there are other major outcomes that defined the 1990s labour market as well, and this review encompasses them. The paper is split in two parts: (1) macrolevel outcomes, and (2) distributional outcomes.

Many of the findings presented have been previously reported. The paper presents new information on job creation and destruction, and the macro-level outcomes (employment, unemployment, etc.) after accounting for the dramatic rise in the human capital of Canadian workers. Rather than simply reviewing the major outcomes, the paper asks to what extent the major events are consistent with prevailing notions regarding an enduring change in the nature of work. 


\section{Why Would the 1990s Labour Market Have Deviated from the 1980s?}

The 1990s labour market has been buffeted by a range of economic forces. First, demand-side shifts associated with trade and technology are thought to have resulted in considerable structural change in the labour market. This is part of the notion of a move to a "knowledge-based economy". Second, perhaps the single most important factor influencing labour market outcomes in the 1990s has been the weak aggregate demand. Gross domestic product grew at an annual average rate of almost $3 \%$ over the 1980s (1980-89), but at only $1.8 \%$ over the 1990s to date (1989-98). This weak GDP growth obviously contributed to the weak employment growth, which in turn could affect other outcomes, such as the shift to self-employment and depressed labour market flows.

Third, change in the way in which firms manage their workforces may have affected labour market performance. Betcherman and Lowe (1997) argue that there are six threads that run through employers' search for a new model of management: global integration, technological change, innovations in work organization, business rationalization, the pursuit of high performance workplaces, and new forms of labour relations. To date, we know little about the extent to which most of these phenomena are taking place in Canadian firms, let alone their effect on labour market outcomes. ${ }^{1}$

Fourth, the supply-side of the labour market has undergone substantial change. Most notably, the supply of highly educated workers has been rising dramatically, and the number of less educated workers falling. There are two important dimensions of this rapid increase in the educational qualifications of Canadians. The educational attainment of women rose quite significantly relative to men. As well, the educational attainment of experienced workers increased relative to the young. The age (experience) structure of the labour market also changed. On average, workers are much more experienced in the 1990s than during previous decades. The human capital imbedded in Canadian workers rose significantly.

Fifth, the institutional landscape is different in the 1990s. EI changes could influence structural unemployment, employment and the income of low-income Canadians in the 1990s relative to the 1980s. ${ }^{2} \quad$ The major revisions to the the social assistance system in many provinces in both the late 1980s (expansion) and the mid-1990s (contraction), and the introduction of the Child Benefit System by the Federal government could also affect both incomes and employment among low-income Canadians. It is probably too early to assess the effect of these changes. Minimum wages have changed little since the early 1980s, but the unionization rate has fallen somewhat (Sargent, 1999). The institutional framework of the 1990s is not that of the 1980s.

1 The quantitative data to assess such effects on a broad scale simply does not exist although with the implementation of the Workplace and Employee Survey by Statistics Canada in 1999, it is hoped that this gap will be at least partially filled. Smaller scale surveys (e.g. Working with Technology, Betcherman and McMullen, 1986) and qualitative studies of the interaction of "hard" technologies (capital investement) and "soft" technologies (organizational structures and human resource practices) have been done (e.g. Osberg, Wein and Grude 1995).

2 Notably, changes to the EI program could have a significant effect on labour market performance, Sargent (1998) constructed an "EI disincentives index" for Canada, and showed that disincentives to work embodied in the EI system fell through the 1990s, and by 1997 were roughly back to the level observed around the 1971 reform. 


\section{Summary of 1990s Outcomes}

A series of complex forces influenced the 1990s labour market. The following is a summary of some of the most significant outcomes.

\section{Macro-Level Outcomes}

1. Associated with the weak economic recovery was a lack of employment creation in general, but in particular, there was little full-time paid job creation in the 1990s, at least until the more rapid growth beginning in 1998.

2. There was a substantial shift in the types of jobs created (more self-employment in particular), but it is not clear that this represents an enduring shift in the nature of work and the way in which firms engage labour. Current research is not conclusive on this issue.

3. Increased downsizing during the 1990s recovery played a major role in the slow employment growth, but it is not clear that this was driven by increased competition and technology, as it was found mainly in the public and consumer services sectors.

4. Contrary to the expectations of many, job stability did not fall in the 1990s, and if anything it increased. This is not necessarily a good news story, however, as it was associated with a weak labour market and depressed hiring and quit rates. Labour mobility and job tenure behaved much as one would expect in a weak labour market.

5. The likelihood of experiencing a permanent layoff did not increase in the 1990s (at least to 1995), but hiring was suppressed. Firms adjusted to slow employment growth by reducing hiring rather than increasing layoffs.

6. Participation rates fell, primarily among young students and due in large part to increased school enrolments. In the aggregate, unemployment behaved much the same during the 1990 s as 1980s recovery in terms of rate, incidence and duration. It remained at a high level by historical standards, but there is little evidence of a continued increase in the level during the 1990s.

7. The human capital (education and experience) imbedded in the labour force increased dramatically through the 1990s (and 1980s), and while there was little change in the "relative" labour market outcomes of workers with more or less human capital, there was a marked deterioration (in an "absolute" sense) in unemployment and job holding for workers with a given level of human capital, particularly among men.

8. Although productivity growth increased at the same rate over the 1990s as the 1980s, growth in national income as measured by GDP/capita slowed significantly, and median family earnings fell if anything. Why the slowdown in income growth with no change in productivity growth? The answer lies in the depressed growth in employment, and the employment/population ratio.

\section{Distributional Outcomes}

1. Throughout the 1980s and 1990s there was a substantial shift in relative educational attainment of different groups which may have influenced relative outcomes of the old vs. young, and young men vs. young women and older men.

2. There was a continued (but perhaps slowed) decline in real earning of recent labour force entrants, particularly young men and recent male immigrants. This may represent an enduring downward shift in lifetime earnings for these groups. 
3. In spite of notions regarding the shift to the knowledge-based economy, there was little evidence of change in the relative outcomes of more vs. less educated. This outcome is related to supply side changes.

4. A major story of the 1990s, to which relatively little attention has been paid, is the change in the relative labour market outcomes of men and women. There have been significant improvements in labour market outcomes for women (earnings, employment, unemployment), and a general deterioration for men. Aggregate trends often mask this underlying and offsetting tendency of the 1990s labour market. Supply side changes may in part explain this shift, but other factors are likely involved.

5. Although there was only a marginal increase in individual earnings inequality in the 1990s, it rose for men, and not for women. More important from a welfare perspective is that family earnings inequality rose. As well, the low-income rate rose unexpectedly during the mid1990s recovery, the first signs of such a "structural" rise through the 1980s and 1990s.

While technological change increased the demand for highly-skilled labour, this was offset by supply-side shifts. Technology may play less of a role in other distributional outcomes, however. It is not likely that technological change is a plausible explanation for many of the 1990s outcomes, such as (1) the declines in real earnings of recent labour force entrants (mainly among males), (2) rising male earnings inequality but stable female inequality, and the rise in family earnings inequality, and (3) the improving position of women, deteriorating outcomes for men. These phenomenon may be more related to supply side or institutional factors. However, surprisingly little is known regarding the underlying causes of many of these distributional outcomes. A number of puzzles persist. The 1990s labour market differed from the 1980s over a range of dimensions, many of which are outlined above. A research agenda that focuses on underlying causes is needed in a number of areas.

\section{Part A. Macro-Level Trends}

\section{Employment and Unemployment}

\section{Does the Rise in Self-Employment Suggest a Fundamental Shift in the Nature of Work?}

If seeking a fundamental shift in the nature of work between the 1980s and 1990s, perhaps the most significant macro-level trend was the rise in importance of self-employment, and the weak expansion over the cycle in full-time paid jobs. Total employment growth was very weak during the 1990s relative to the 80s. This occurred in an environment of slow growth in GDP (Figure 1). The traditional gains in full-time paid employment were replaced in the 1990s labour market largely by own-account self-employment (Figure 2). Over the 1990s cycle to date (1989 to $1998)^{3}$, full-time paid jobs accounted for only $18 \%$ of all net job creation in Canada. Over the 1980s cycle, this was 58\%, and in the U.S. during the 1990s it was 75\% (Figures 3 and 4). Self-

3 We focus on 1981-89 and 1989-98 in much of this analysis. From an annual perspective, 1981 and 1989 were years of peak labour market performance. Furthermore, when making comparisons between decades, we attempt to focus on years that are comparable. The recessions ended in 1982 and 1992 and we compare years that are equally spread in time from those years. For example, we compare, 1998 to 1988. 
employment $^{4}$ accounted for about $58 \%$ of the net change during the 1990 s, only $18 \%$ during the 1980 s, and $6 \%$ in the U.S. during the 1990s. The strength of self-employment creation varied from year to year, but it remained strong to the end of the period (Figure 2).
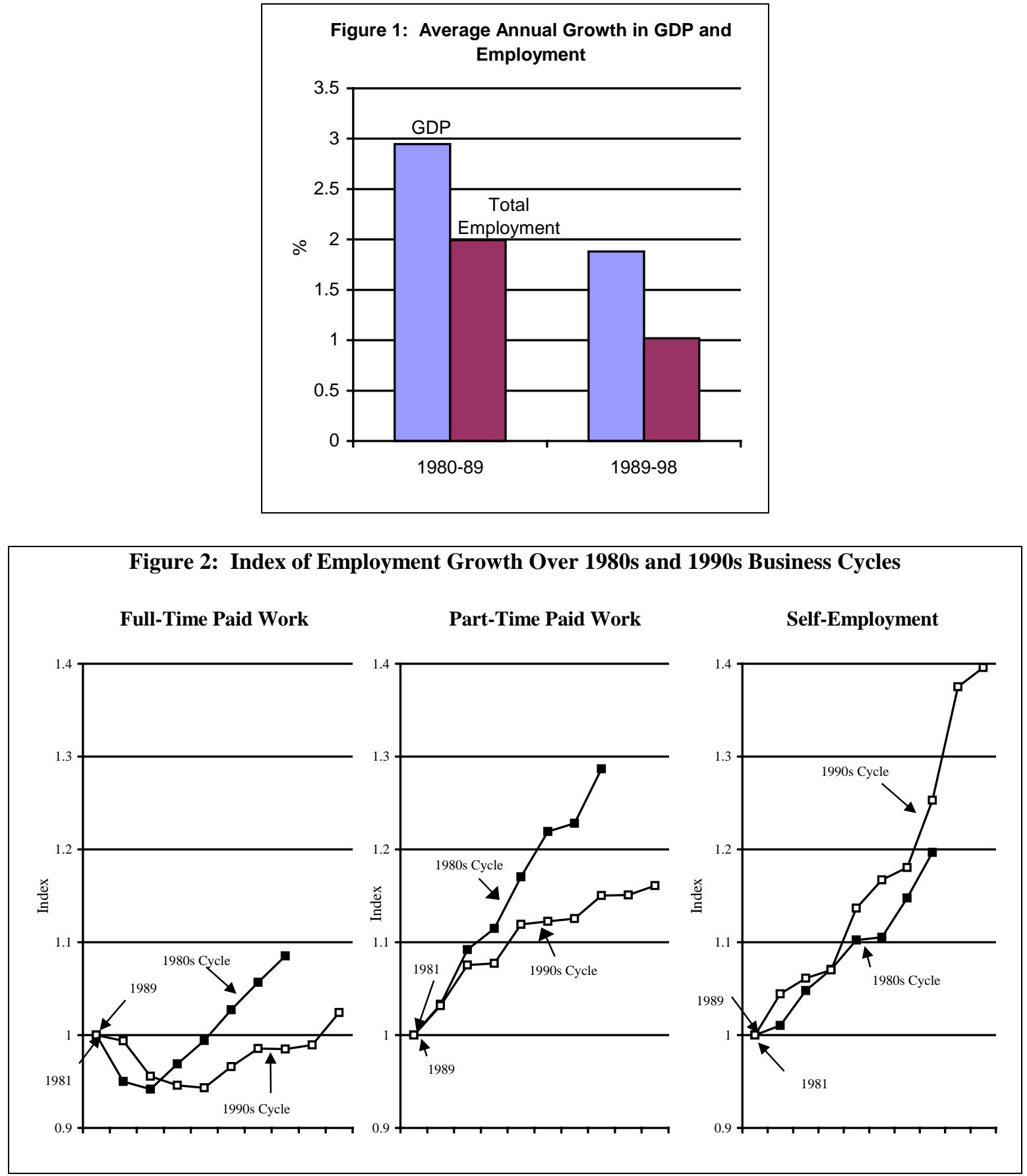

4 Self-employment is not measured on a comparable basis in the official statistics of Canada and the U.S. In the U.S. incorporated self-employed are excluded, and in Canada they are included. Here we render the data comparable. 


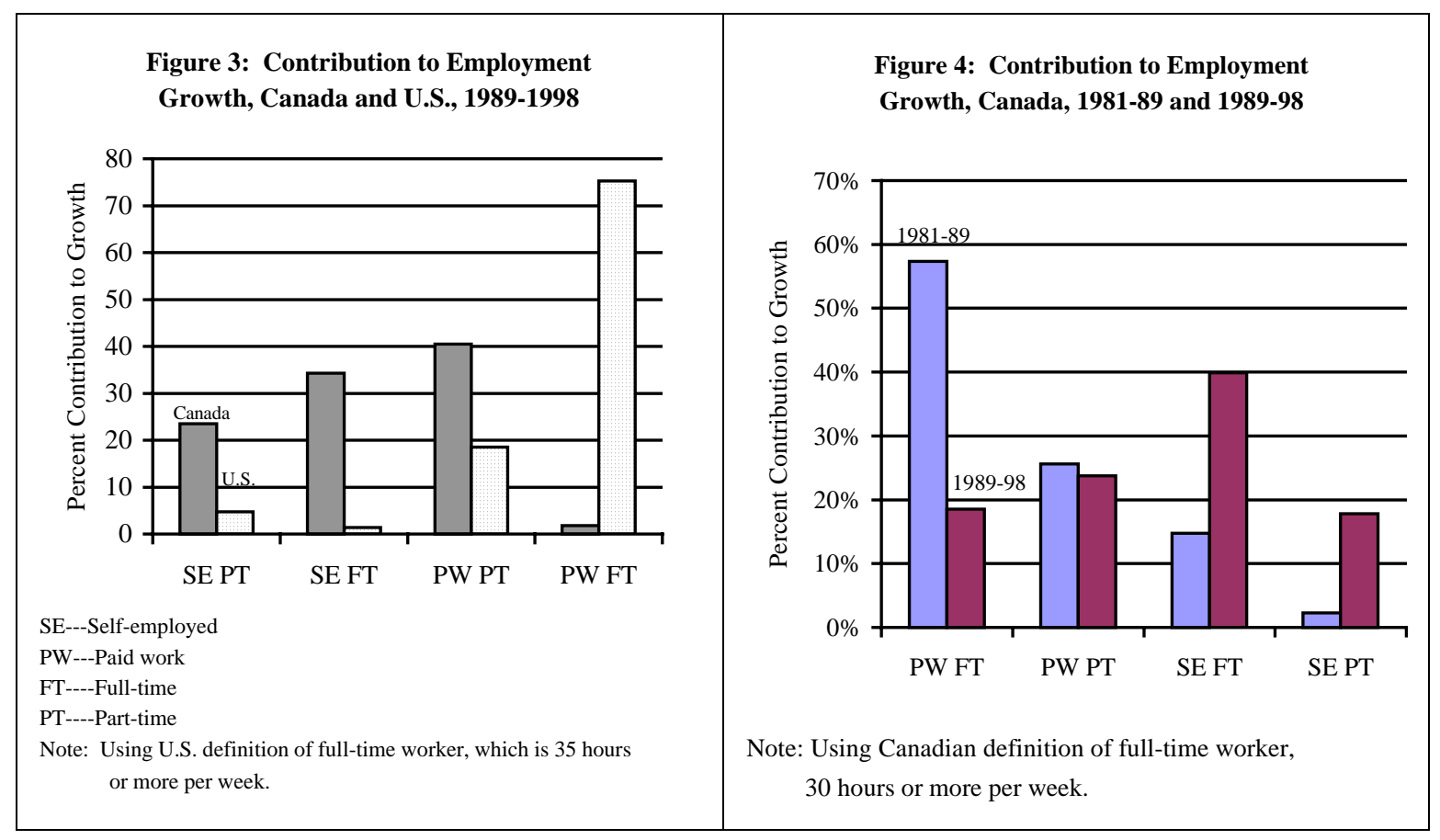

But is this a fundamental shift in the nature of work in Canada? Is it a manifestation of a fundamental change in the way in which companies engage labour, resulting in increased nonstandard or contingent work? It is probably too early to tell. The OECD argues that over the long run, the extent to which self-employment growth in Canada outstripped paid employment is highly correlated with labour market slack (the difference between structural and actual unemployment) (OECD, 1998). With structural unemployment declining in the 1990s (Sargent, 1999), and the aggregate unemployment rate at more or less the same level, labour market slack increased, resulting in more workers turning to self-employment.

But there are other possibilities. Evidence to date has convincingly suggested that there is little correlation between short-run economic conditions (proxied by either the unemployment rate or full-time paid employment rate) and the tendency to be self-employed over the business cycle (Blanchflower and Oswald, 1998; Lin, Picot and Yates, 1999). Over the cycle, workers in Canada are not increasingly "pushed" into self-employment by deteriorating labour market conditions. However, over a longer period with persistently high unemployment and increasing labour market slack, the "push" hypothesis may be more tenable.

But if this trend represents a fundamental shift in the nature of work, why is it not observed in the U.S. where competitive pressures have presumably been similar? One study concluded that differences in the growth of personal tax rates may be a major reason for the Canada/U.S. difference (Schuetze, 1998). Other possible factors not considered in studies to date include differences in the growth of payroll taxes, and the effect of the financing of health care in the U.S. There is a very strong incentive for American workers to be in paid jobs, as their medical coverage is financed in this way.

Puzzles remain regarding the reasons for both the rise in self-employment in Canada in the 1990s, and why this was observed in Canada and not the U.S. Institutional differences between the countries may result in a fundamental shift in the nature of work, which manifests itself in different ways in the two countries. It may also be that the weak economic recovery of the 1990s in Canada drove this phenomenon, and it will reverse itself. Further research is needed. 


\section{Labour Force Participation and the Incidence and Duration of Unemployment}

The aggregate labour force participation rate has not fully recovered from the decline in the early 1990s, and in the face of poor employment growth, it has remained depressed throughout the 1990s (Figure 5). Studies have shown that most of this depressed rate is due to declines among young workers and older males. For example, an updated version of Sunter and Bowlby (1998) computes the shortfall in labour force participation during 1998. This shortfall is the difference between the observed values and what one would expect if applying the rates at the last business cycle peak, 1989. Forty one percent of the shortfall is among male youth, 30\% female youth, and $31 \%$ among males over age 55 . Over $70 \%$ of the aggregate shortfall was among youth, and most of this was due to falling rates among students, and the increased tendency of students to stay in school (Figure 6) (Jennings, 1997; Sunter and Bowlby, 1998). These participation rate declines among youth were likely related to deteriorating job opportunities, and the belief that higher levels of education were required to compete in the labour market (this latter point could result in some positive outcomes). While in the aggregate there was little change among prime aged workers, this masked deterioration among males, and improvements among women. Among 2554 year olds, participation was 36\% lower in 1998 than one might have expected (based on the patterns of 1989) among men, and 37\% higher among women.

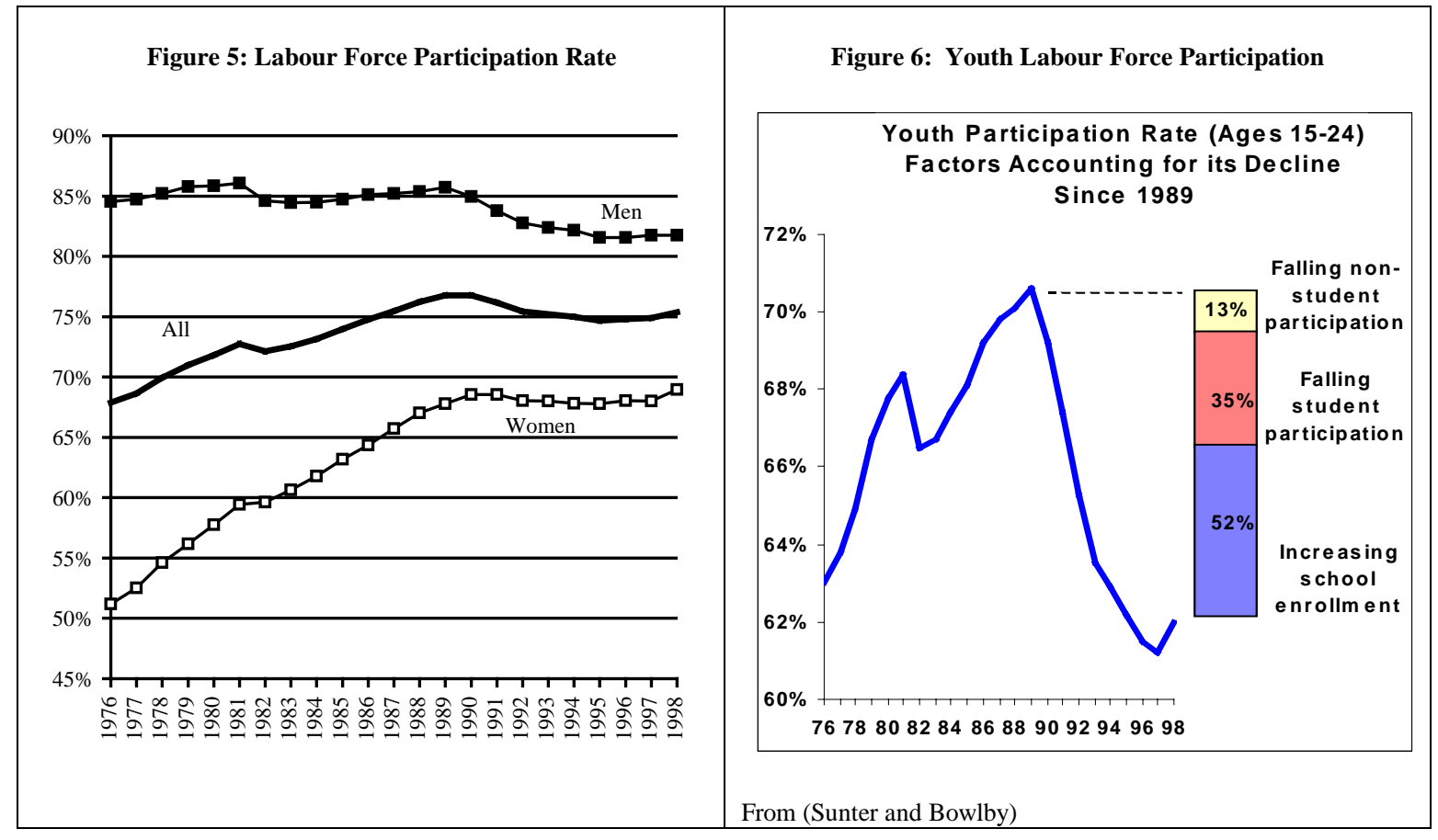

With somewhat "suppressed" participation, the unemployment rate fell at about the same rate during the 1990s recovery as it did during the 1980s, although it remained high longer during the 1990s than 1980s recession (Figure 7). Using a technique outlined by Corak and Heisz (1996) to compute incidence and expected duration of completed spells of unemployment, one observes that duration is marginally higher, and incidence marginally lower in the 1990s (compared to the 1980s); there was not an important change in either component of unemployment (Figure 8). ${ }^{5}$

5 As Sargent (1999) points out, data on uncompleted spells of unemployment from the Labour Force Survey show a more substantial increase in unemployment duration between the 1980s and 1990s. The difference is due to underlying methodologies. The approach used here computes expected duration of new spells, and the LFS reports durations of all existing spells. The later approach oversamples long spells and results in an upward bias in duration. Furthermore, a marginal change in the average length of a new spell can cause a more substantial 
There is little evidence of a rising level of unemployment in the 1990s cycle compared to the 1980s, although by historical standards, unemployment was high during both of these cycles.

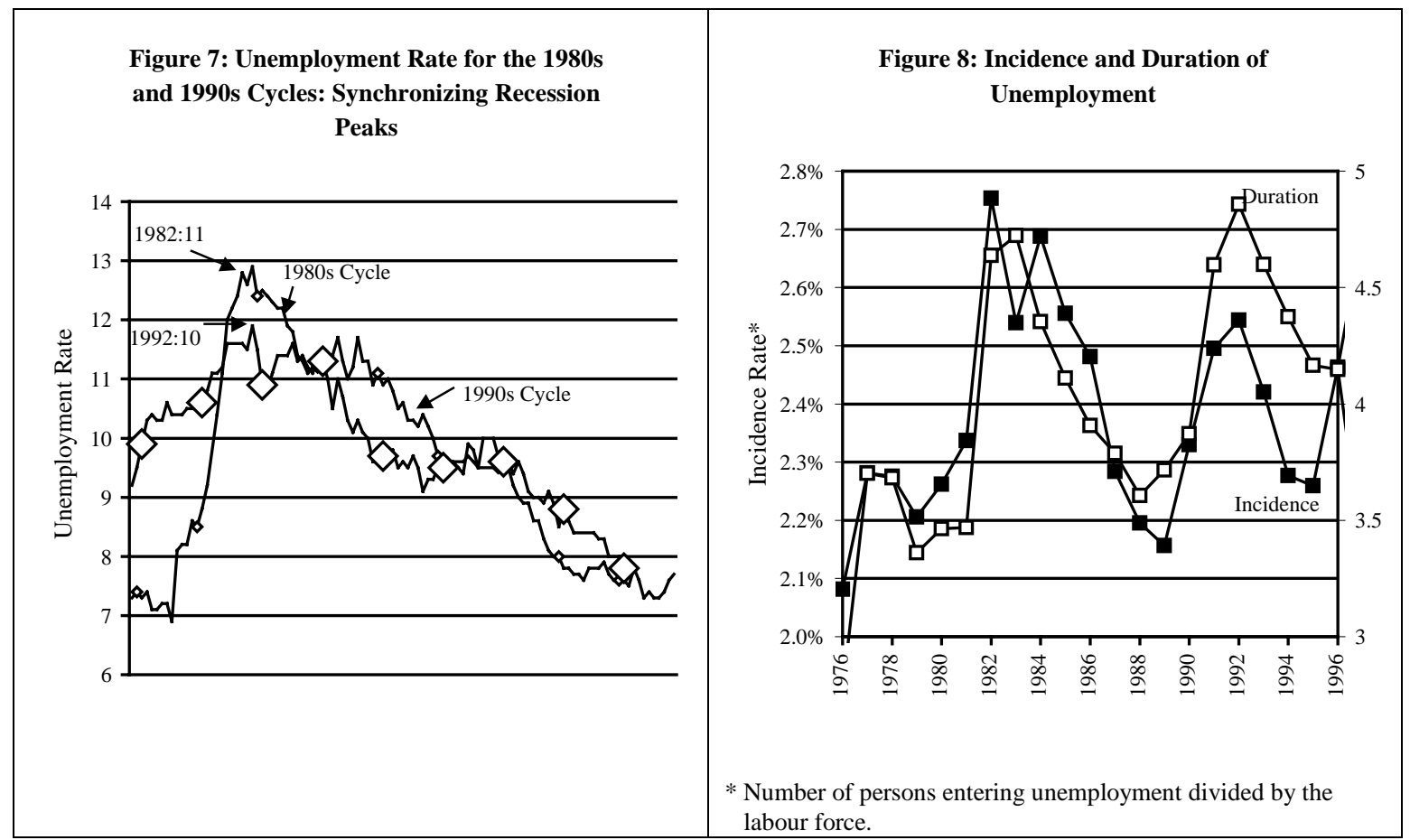

\section{The Decline in Labour Market Outcomes for Workers with a Given Level of Human Capital}

Both the 1980s and 1990s witnessed a remarkable supply-side shift in the quality of workers. The human capital embodied in the labour force, both in terms of education and experience, rose. The rapid growth in the educational attainment of workers in particular has been noted by various researchers (e.g. Riddell, 1995). The number of degree holders increased at an annual average rate of $5.4 \%$ since the mid-1970s (Table 1), while workers with high school or less remained constant. The net result was that the share of the labour force with a university education rose from about $10 \%$ in 1976 to $18 \%$ in $1998^{6}$ (Table 2). The experience levels (as proxied by age) of the labour force changed almost as rapidly. The number of mature (45-54) workers rose $4.8 \%$ per year in the 1990s, while the number of less experienced workers (under 35) fell at around $1.1 \%$ per year.

change in the average duration of the stock of in-progress spells as the stock of unemployed becomes more heavily weighted with workers in the midst of long spells. From 1994 to 1996 the average unemployment spell lasted 4.1 months compared to 4.0 months a decade earlier. Meanwhile, the average length of time workers (sampled at a point in time) have been unemployed rose from 4.9 to 5.7 months. Thus, while the proportion of new unemployment spells that go on to become long spells is not substantially longer in the 1990s, at any point in time the average unemployed worker is more likely to be in the midst of a long spell.

6 A change in the educational classification in the LFS in 1989 makes comparisons before and after that year difficult. However, estimates of degree holders past 1989 are biased downwards compared to those prior to 1989. 
Table 1: Changes in the Demographic Composition of the Labour Force

Men

Educational Attainment

High School Graduation or less

Some Post Secondary, but less than University

University or higher

Age

$15-24$

25-34

$35-44$

45-54

$55-64$

\begin{tabular}{|c|c|c|c|}
\hline \multicolumn{4}{|c|}{ Average annual growth rate } \\
\hline 1976-80 & $1981-89$ & $1991-98$ & 1976-1998* \\
\hline \multicolumn{4}{|c|}{ (percent growth) } \\
\hline 2.8 & -0.6 & -2.0 & -0.5 \\
\hline-0.7 & 4.6 & 3.0 & 3.0 \\
\hline 4.7 & 4.2 & 3.9 & 4.2 \\
\hline 2.6 & -1.7 & -1.2 & -0.7 \\
\hline 2.9 & 1.8 & -1.3 & 0.8 \\
\hline 2.8 & 3.7 & 2.3 & 3.0 \\
\hline 0.4 & 1.1 & 4.1 & 2.1 \\
\hline 1.7 & 0.0 & 0.2 & 0.5 \\
\hline
\end{tabular}

Women

Educational Attainment

High School Graduation or less

Some Post Secondary, but less than University

University or higher

Age

$15-24$

25-34

$35-44$

$45-54$

$55-64$

Both

Educational Attainment

High School Graduation or less

Some Post Secondary, but less than University

University or higher

Age

$15-24$

25-34

$35-44$

45-54

$55-64$

* excludes 1990

$\begin{array}{cccc}5.4 & 0.7 & -2.1 & 0.5 \\ 2.3 & 6.2 & 3.6 & 4.5 \\ 9.8 & 8.2 & 5.9 & 7.6 \\ & & & \\ 3.5 & -1.2 & -1.1 & -0.3 \\ 7.5 & 4.0 & -0.9 & 2.8 \\ 6.5 & 6.8 & 2.6 & 5.1 \\ 2.7 & 3.8 & 5.5 & 4.2 \\ 4.0 & 1.4 & 2.1 & 2.2\end{array}$

0.5

.5

7.6

$-0.3$

2.8

4.2

2.2

$\begin{array}{rrrr}3.8 & -0.1 & -2.0 & -0.1 \\ 0.6 & 5.4 & 3.3 & 3.7 \\ 6.2 & 5.7 & 4.9 & 5.4 \\ & & & \\ 3.0 & -1.5 & -1.2 & -0.5 \\ 4.6 & 2.7 & -1.1 & 1.6 \\ 4.1 & 4.9 & 2.4 & 3.8 \\ 1.2 & 2.2 & 4.8 & 3.0 \\ 2.5 & 0.5 & 0.9 & 1.0\end{array}$


Table 2: Labour Force by Educational Attainment

\begin{tabular}{|c|c|c|c|c|c|}
\hline & 1976 & 1981 & 1989 & 1990 & 1998 \\
\hline Men & \multicolumn{5}{|c|}{ (fraction of total) } \\
\hline \multicolumn{6}{|l|}{ Educational Attainment } \\
\hline High School Graduation or less & 0.68 & 0.68 & 0.60 & 0.51 & 0.41 \\
\hline Some Post Secondary, but less than University & 0.21 & 0.19 & 0.25 & 0.34 & 0.41 \\
\hline University or higher & 0.11 & 0.12 & 0.16 & 0.15 & 0.18 \\
\hline Total Men & 1.00 & 1.00 & 1.00 & 1.00 & 1.00 \\
\hline \multicolumn{6}{|l|}{ Women } \\
\hline \multicolumn{6}{|l|}{ Educational Attainment } \\
\hline High School Graduation or less & 0.67 & 0.67 & 0.56 & 0.50 & 0.38 \\
\hline Some Post Secondary, but less than University & 0.25 & 0.24 & 0.30 & 0.37 & 0.44 \\
\hline University or higher & 0.07 & 0.09 & 0.14 & 0.13 & 0.18 \\
\hline Total Women & 1.00 & 1.00 & 1.00 & 1.00 & 1.00 \\
\hline \multicolumn{6}{|l|}{ Both } \\
\hline \multicolumn{6}{|l|}{ Educational Attainment } \\
\hline High School Graduation or less & 0.68 & 0.68 & 0.58 & 0.51 & 0.39 \\
\hline Some Post Secondary, but less than University & 0.22 & 0.21 & 0.27 & 0.36 & 0.42 \\
\hline University or higher & 0.10 & 0.11 & 0.15 & 0.14 & 0.18 \\
\hline Total & 1.00 & 1.00 & 1.00 & 1.00 & 1.00 \\
\hline
\end{tabular}

Note: Educational classifications prior to 1989 are not comparable to those post-1989, and hence we include both 1989 and 1990 to provide some idea of the difference

To evaluate labour market performance from a workers perspective, one would want to know how the market performed for a given level of human capital. Has the unemployment rate increased for workers with a particular level of experience and education? What about the likelihood of having a job? The aggregate employment and unemployment statistics mask answers to such questions since they do not account for compositional change. Thus, we compute adjusted unemployment, paid employment to population, and labour force participation rates which account for the effect of changes in labour force composition. ${ }^{7}$ These adjusted rates reflect the labour market status of workers with a representative level of human capital.

7 As an example, let us consider the unemployment rate

$$
U R_{t} \equiv{ }_{i=1}^{30} s_{i t} U R_{i t} .
$$

The unemployment rate (UR) at time $t$ is equal to the weighted sum of group specific unemployment rates in that period $\left(\mathrm{UR}_{\mathrm{i}}\right)$ where the weights equal the share of the labour force accounted for by group $\mathrm{i}\left(\mathrm{s}_{\mathrm{i}}\right)$. Changes in the unemployment rate therefore derive from changes in the composition of the labour force and changes in group specific unemployment rates. Holding $\mathrm{s}_{\mathrm{it}}$ constant at $\mathrm{t}=1$ levels we can construct an adjusted unemployment rate that controls for the change in the human capital composition of the labour force. We define 30 demographic subgroups (i) stratified by age (5 groups), educational attainment ( 3 groups) and gender. The change in educational classification in the LFS in 1989 requires that we exercise caution in comparing post-1989 data with earlier years. This should not greatly affect our results, since our analyses make use of rates. The changes in classification will affect the level, of say, the unemployment (U) with degrees. But it affects the level of the labour force with degrees in a similar manner. Hence, when calculating the rate (U/LF), the changes will tend to cancel out, leaving the rate unaffected although the levels of both the numerator and denomination will have been affected in likely similar ways. Visual inspection of the time series data suggest that this "cancelling-out" took place, with changes between 1989 and 1990 appearing to stem only from cyclical factors, not changes in the classification system. Nevertheless, we adjusted post-1989 data to test the sensitivity of our results to this assumption. We found that if anything, our results are strengthened by this. In this study we present only unadjusted results. 
We start with the results for men. The performance of the labour market for a male worker with a representative level of human capital deteriorated considerably between the 1980s and 1990s. Between 1988 and 1998 the participation rate was 8\% lower, unemployment was 2 percentage points higher, the proportion employed fell by 8 percentage points (Figures 9 to 11). In general this deterioration was not unique to any particular group...younger, older, the more or less highly educated. It was observed among all groups (Appendix, Figures 1 to 3). The severity was, if anything, greater among the more experienced, more highly educated males, the very group one would expect to benefit from a labour demand shift that favoured those with greater human capital.
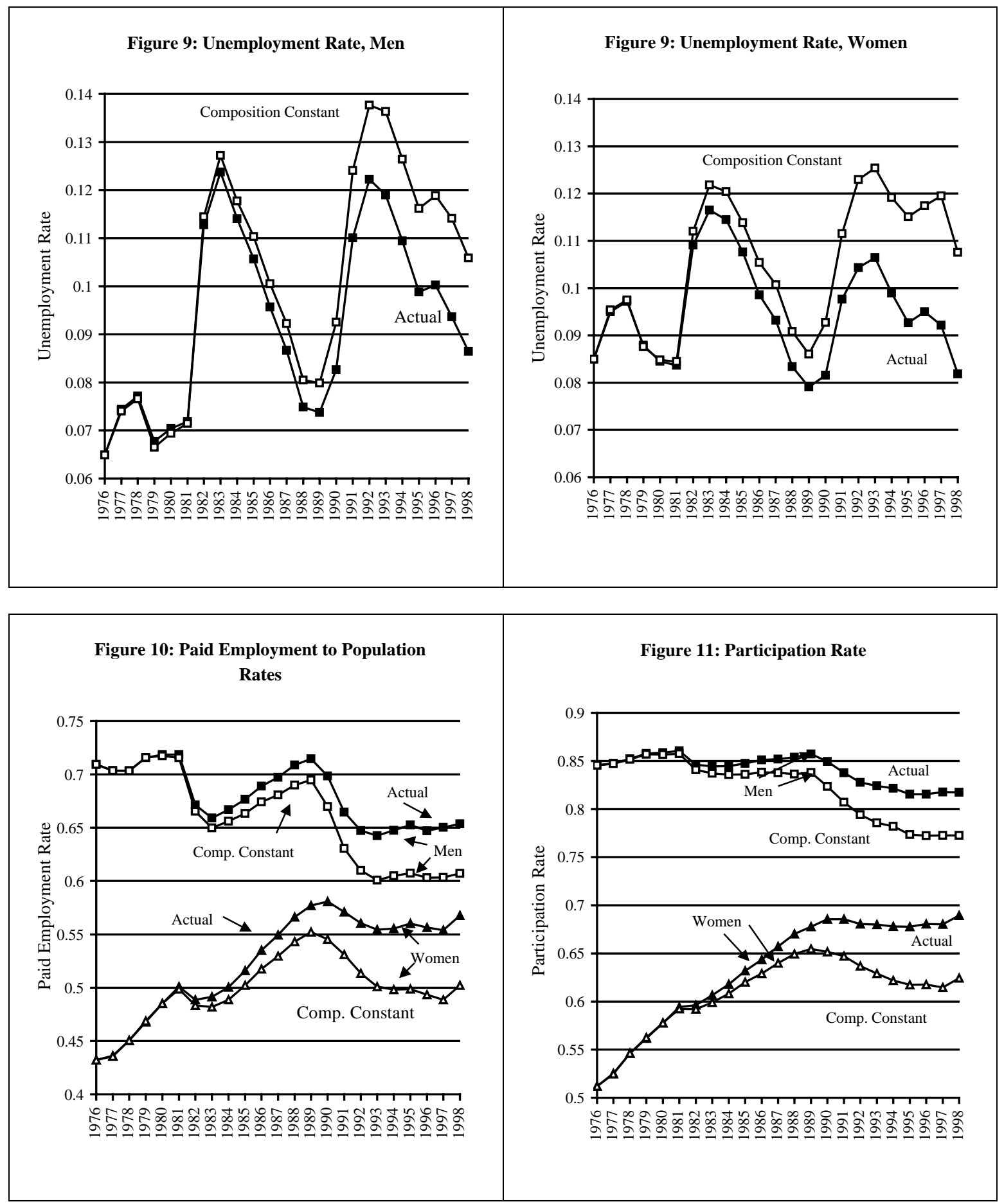
For a female worker with a representative level of human capital (education and experience), labour force participation fell 2.5 points, unemployment rose 1.6 percentage points, and the paid employment rate fell 4 percentage points, a substantial decline but smaller than for men. Was this deterioration in labour market outcomes observed across all age/education groups? There was little change in the labour market outcomes presented here for prime aged universityeducated women. This is consistent with findings from Finnie (1998) on outcomes for university graduates. This is in contrast to men, where declines were significant among the prime aged and more highly educated. Among women, the very young workers and older workers were most negatively affected (Appendix, Figures 1 to 3).

To summarize, while unemployment trends in the 1990s resembled those of the 1980s, a worker with a given level of education and experience saw the unemployment rate rise and likelihood of holding a job decline.

\section{Hiring, Labour Turnover and J ob Tenure}

\section{Do Trends in Aggregate J ob Stability, Hiring and Labour Mobility Suggest Fundamental Change in the Nature of Work?}

The story of the 1990s regarding labour flows appears to be relatively straightforward, at least to the mid-1990s ${ }^{8}$ when available data ceases. Employers reacted to the suppressed paid employment growth by reducing hiring rather than increasing layoffs. Focusing on years with roughly the same elapsed time since the recession ends, 1984-86 and 1994-96, new hires as a proportion of employment were at $20 \%$ during the mid-1990s, down from $24.4 \%$ during the mid1980s (Figure 12). There was little recovery in hiring following the 1990s recession. This lower hiring rate would affect younger workers and new labour force entrants in particular.

8 Labour flow data come from the Longitudinal Worker File (LWF), an administrative data source developed by the Business and Labour Market Analysis Division of Statistics Canada. This file relies on taxation and EI data, and this data lags the reference period by two years or more. The LWF gives quits, permanent layoffs, temporary layoffs and other separations at the company level. Hires are derived from the same source at the economy or industry level, and represent replacement and expansionary hiring. These flows measure full- and part-time jobs. See Statistics Canada Catalogue Number 71-539-XPB, "Permanent Layoffs, Quits and Hirings in the Canadian Economy, 1978-1995" for more detail. 


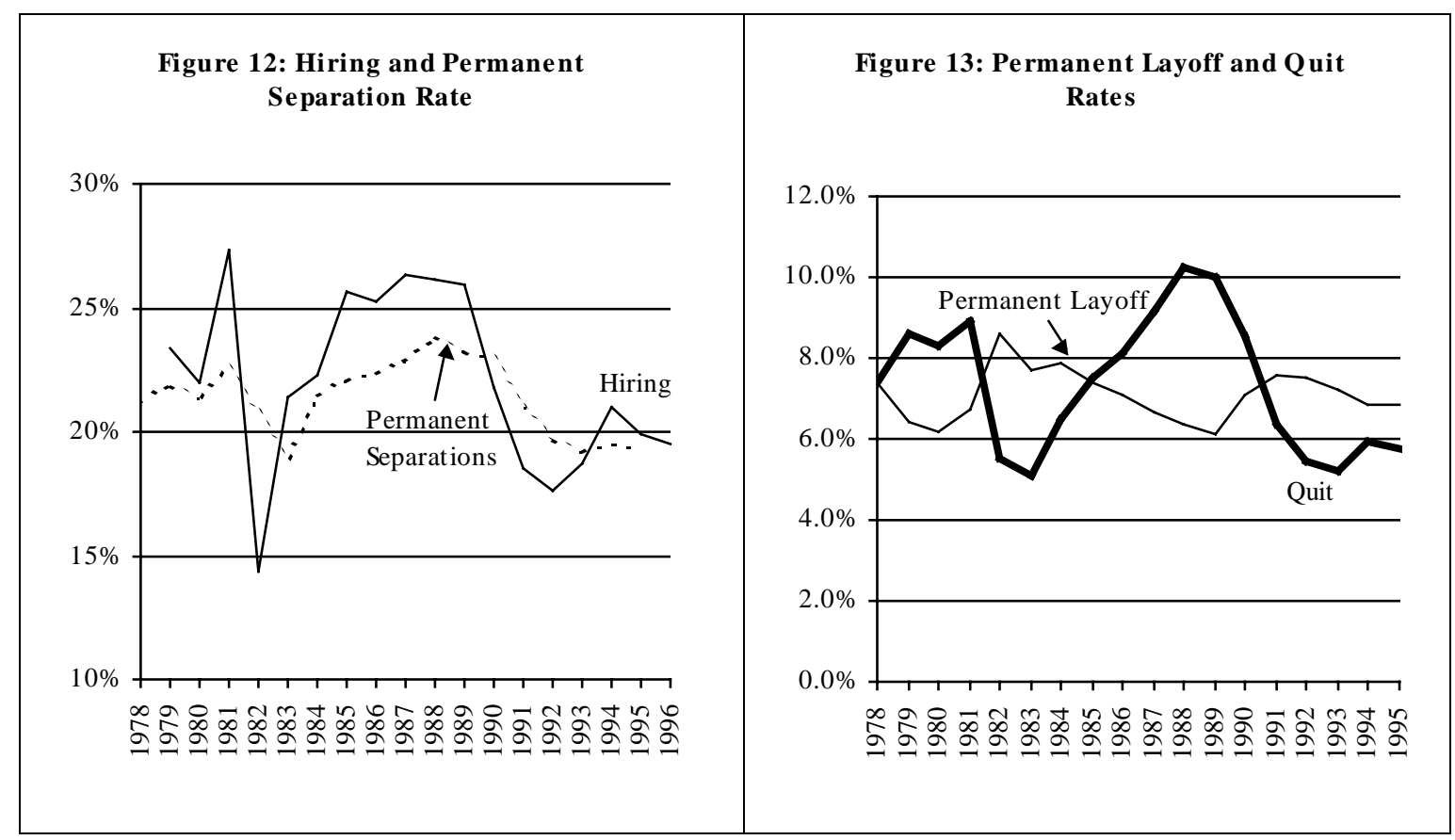

Hiring rates were low (relative to the 1980s), but in spite of the concern regarding job loss, the likelihood of being permanently laid off did not increase during the 1990s cycle, at least to the mid-1990s. This can be seen in the raw data (Figure 13), and holds after controlling for changes in the composition of the workforce (Picot and Lin, 1996). In the face of poor job opportunities, quit rates are also lower than in the 1980s. The average quit rate of the 1993-95 period was 5.6\%, down from $7.4 \%$ during the $1983-85$ period. With lower quit rates, and no substantial rise in permanent layoffs, the likelihood of a worker permanently separating from their firm actually fell in the early 1990 s compared to the 1980 s (19.3\% in 1993-95, compared to $22.0 \%$ during $83-85$ ) (Figure 12). Lower hiring and permanent separation rates means that labour mobility fell between the two decades, at least to the middle of the 1990s decade. The rate at which labour was reallocated among firms in response to structural change or inter-firm competition slowed during the 1990 s.

Along with lower labour turnover comes increasing job tenure. In spite of the concern regarding job stability, average job tenure ${ }^{9}$ in paid jobs has not fallen in Canada, and if anything it has increased (Figure 14) (Heisz, 1999, Green and Riddell, 1996). The expected completed length of a new job rose from an average 45 months during 1983-86, to 50 months in 1993-96. This is not necessarily a positive sign, as it reflects at least in part the lower quit and hiring rates, which in turn reflect a weak job market. However, it is in contrast to the popular notion that job stability has fallen.

9 Average job tenure is measured following Heisz (1999). This approach measures the average complete length time a worker just starting a new job can expect to remain with that employer. It measures complete spell lengths and avoids several biases commonly associated with alternate measures of job tenure such as the one regularly reported by the LFS. 


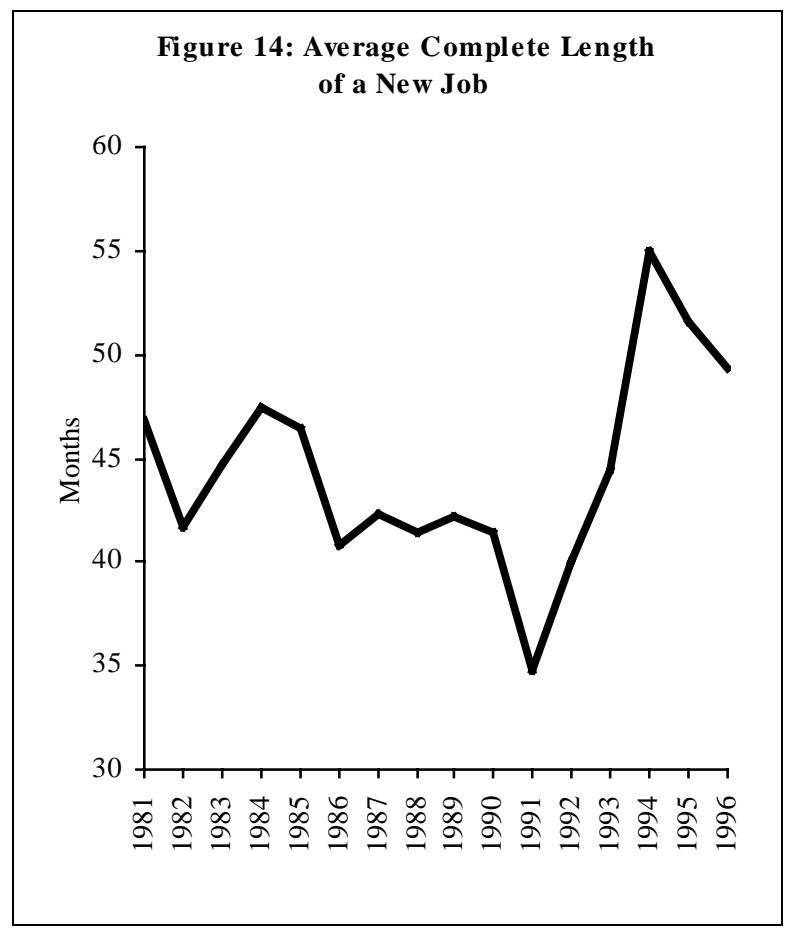

Hence, there has been significant change in labour flows between the 1980s and 1990s. Specifically, the first half of the 1990s saw lower hiring and quit rates, reduced labour mobility, robust aggregate job tenure, and little change in the likelihood of permanent layoff. The change during this period was in the likelihood of getting a job, not in the likelihood of losing it. However, these observations probably do not suggest a structural shift in the way the labour market functions. In light of slow employment growth, these changes are not particularly surprising, except perhaps for the stability in the permanent layoff rate. Even here, however, it has been shown that in response to changes in employment levels during a recession, firms are much more likely to adjust their hiring rate than the permanent layoff rate, which is the least cyclically sensitive of all labour market flows (Picot, Lin and Pyper, 1998).

\section{J ob Creation and Destruction}

\section{Does the Evidence on J ob Destruction and Downsizing Suggest Enduring Change in the Way Firms Manage their Workforces?}

"Downsizing" reflects the notion that firms restructure their work in such a way as to reduce their workforce and reduce labour costs in order to increase competitiveness. This is not a reduction in employment due to a temporary decrease in product demand. Rather, it is a structural change in the way in which work is conducted, and in what work is conducted, so as to reduce labour requirements. Such action would influence paid employment growth, which was quite weak during the 1990 s.

Regular labour force data cannot inform us regarding downsizing since data the company level are required. Data on job creation and destruction ${ }^{10}$ can be generated for the entire economy from the LEAP data set, a longitudinal file of all companies (with employees) in the Canadian

10 The concept of job creation and destruction was pioneered by Birch (1987), Leonard (1987) and Davis, Haltiwanger and Schuh (1993) in the U.S., and Baldwin, Dunne and Haltiwanger (1994) in Canada. 
economy. ${ }^{11}$ Between any two years, job creation is the increase in employment observed in companies which are expanding, and job destruction (or loss) the decrease in employment in all companies contracting. The job loss rate is the total job loss divided by total employment in all firms (expanding and contracting). Net employment change, which is reported by the LFS, is simply the difference between job gain and job loss. The employment growth rate routinely reported is simply the difference between the job creation and destruction rates.

One would expect to see an increase in job destruction in the 1990s relative to the 1980s if downsizing was a significant phenomenon. Such an increase is observed (Figure 15). Comparing 1984-86 to the 1994-96, two periods that are roughly in the same position in the economic recovery, the job destruction rate is roughly 1.8 percentage points higher in the latter period. The job destruction rate increased in the recession as expected, but did not fall in the recovery of the 1990s. A decomposition shows that little of this increase was due to a compositional shift in employment towards industries that have high job destruction rates. Most of the increase was within industries. ${ }^{12}$

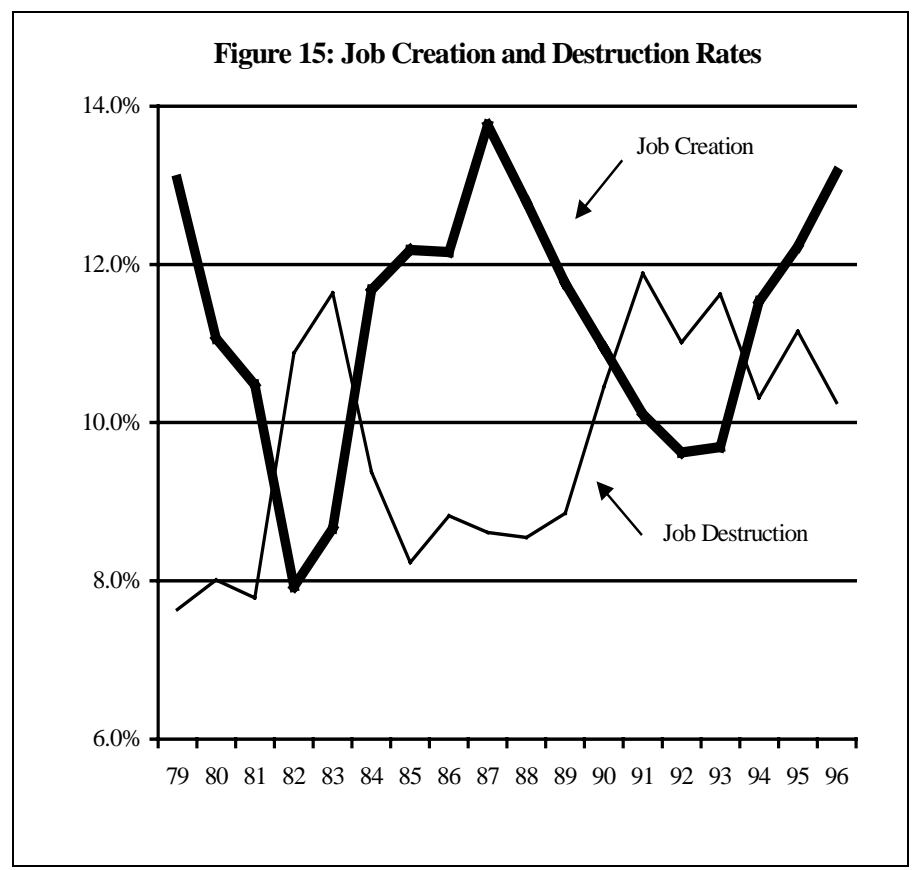

One might expect to observe downsizing due to competitive pressures or technological change in much of the commercial economy, perhaps notably the business services/financial sector, where information technologies expanded rapidly, or the manufacturing sector, which is open to foreign competition. In fact, the lions share of the increase in job destruction is concentrated in the public services (health, education and government sectors) and consumer services industries (Table 3). The public services accounted for nearly $40 \%$ of the rise in job destruction. Virtually all this was concentrated in the health and government sectors. Consumer services accounted for an almost equal share. In contrast, there was little change in the remainder of the commercial economy.

11 LEAP is the Longitudinal Employment Analysis Program, a data set developed and maintained in the Business and Labour Market Analysis Division of Statistics Canada.

12 Job destruction figures increase job losses from continuing firms that are contracting, and firms that die. Likewise job creation includes gains from births and continuing firms that are growing. In practice, most creation and destruction occurs at continuing firms. Furthermore, cyclical changes are derived almost entirely from growth and destruction at continuing firms, not from firm birth and death. 
While the general rise in job destruction supports the notion of increased downsizing among commercial firms, its location does not. The majority of the increase in downsizing was observed in the public and consumer services sectors.

\begin{tabular}{lc}
\hline \multicolumn{2}{c}{ Table 3: Change in the Job Destruction Rate by Industry } \\
\hline \hline Industry & $\begin{array}{c}\text { Rise in Total Job Destruction Rate Accounted } \\
\text { for by Each Industry }\end{array}$ \\
\cline { 2 - 2 } & \\
Primary and Construction & -0.01 \\
Manufacturing & 0.15 \\
Distributive Services & 0.18 \\
Business Services & 0.16 \\
Consumer Services & 0.67 \\
Public Services & 0.69 \\
All Industries & 1.85 Percentage Points \\
\hline
\end{tabular}

Do these data suggest an important change in the way in which firms utilize labour? Did firms downsize at an enhanced level because of increased competition? This may be true for the consumer services sector, but there is little evidence that it holds in the rest of the commercial economy. Overall the increased level of job destruction played a significant role in the slow employment growth of the 1990s, but it was not a widespread phenomenon, covering the commercial sector. The downsizing of organizations in the health and government sector does support the notion of a fundamental shift in these sectors at least. Finally, is the increase in job destruction reconcilable with the lack of an increase in layoffs? As noted earlier, firms adjusted by decreasing hiring rather than increasing layoffs in the 1990s compared to the 1980s. This could hold in downsizing firms as well.

\section{If Productivity Increased at the Same Rate During the 1990s as 1980s, Why the Slowdown in Income?}

A comparison of macro-level labour market trends between the decades would not be complete without focusing on productivity and market earnings. Productivity has increased at about the same rate during the 1980s and 1990s cycles. A recent release by Statistics Canada suggests that commercial sector productivity growth has been in the same order of magnitude during the 1990s as it was during the 1980s, and in fact has changed little since the dramatic slowdown of the early 1970s (Figure 16). This holds for both labour productivity growth (at an annual average growth of around 1\%), and multi-factor productivity (around 0.6\%). Furthermore, for the commercial sector as a whole, productivity growth in Canada and the U.S. during the 1990s has been similar, although the U.S. leads in some manufacturing industries. This is not to say that we should not be concerned about productivity, since these results refer to growth, not level. More detail can be found in Baldwin and Wells, 1999.

However, GDP per capita, an aggregate measure of wealth creation, has slowed in the 1990s, in spite of the stable productivity growth; it grew at an annual average 1.9\% over the 1981-89 cycles, and $0.7 \%$ during the 1989-98 cycle. In an accounting sense one can decompose GDP per capita in the following way: $(\mathrm{GDP} / \mathrm{pop})=\left(\right.$ pop15+/pop) ${ }^{*}(\mathrm{emp} / \mathrm{pop} 15+)^{*}$ (hours/emp) $*$ (GDP/hours). In other words, taking the log of both sides the equation, growth in GDP per capita is the sum of growth in: (1) the share of the population 15+, (2) the employment/population ratio, (3) hours worked per employee, and (4) labour productivity. Hence, even though the growth in labour productivity was similar in the two periods, the growth in the employment/population ratio in 
particular was depressed in the 1990s compared to the 1980s, resulting in lower growth in GDP/capita. (Figure 17, See Baldwin and Wells (1999) for details). While output per hour worked has changed little, the proportion of the population working has fallen marginally over the cycle (compared with expansion in the 1980s). The result is that the growth in GDP per capita slowed in the 1990s.

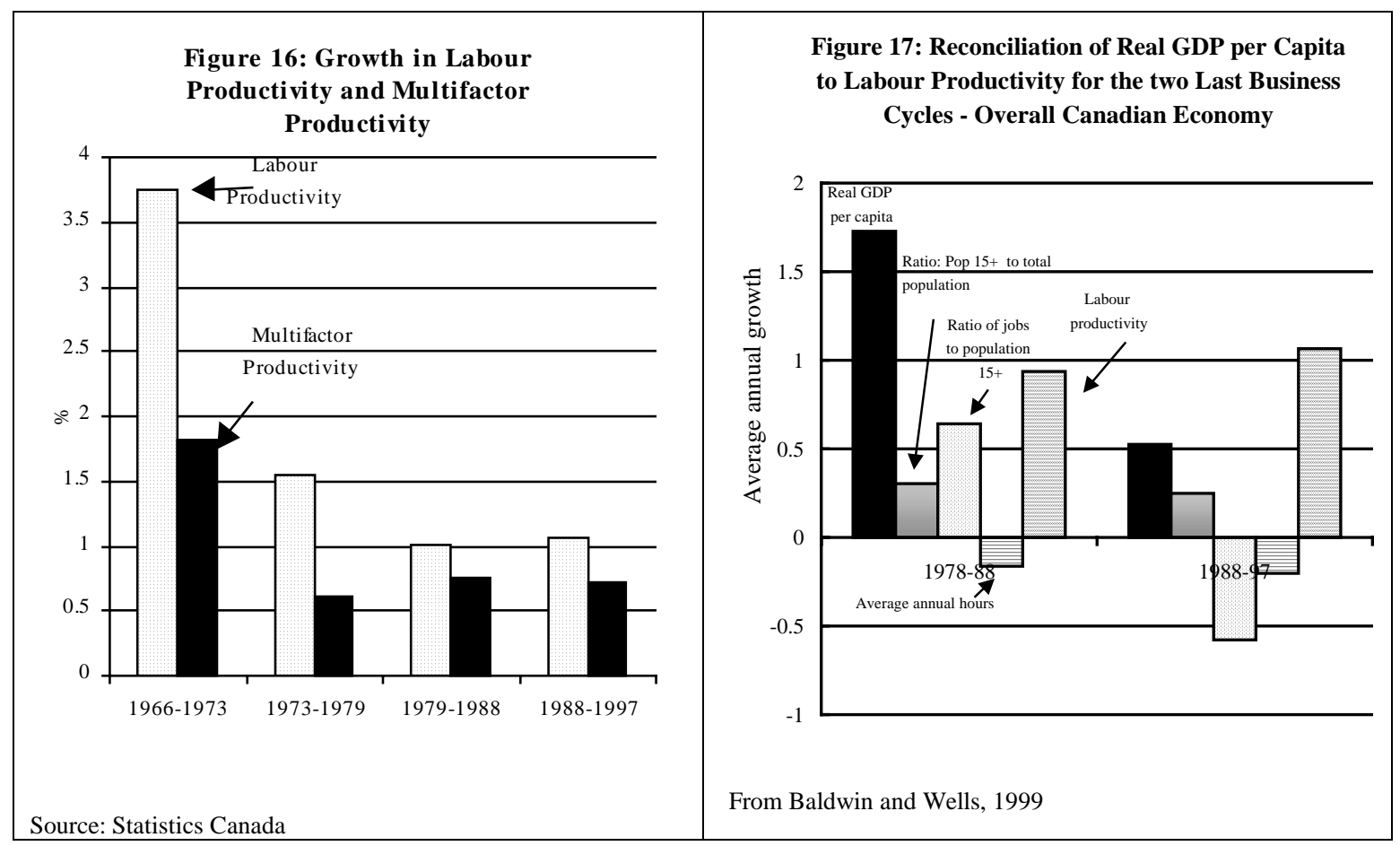

Slow growth in real GDP per capita is reflected in stagnant family earnings growth. Measures from household data suggest little improvement, and perhaps some deterioration, in family earnings during the 1990s. As a welfare measure, median market earnings at the family level indicate stability throughout the 1980s and perhaps a marginal decline during the 1990s (Figure 18).

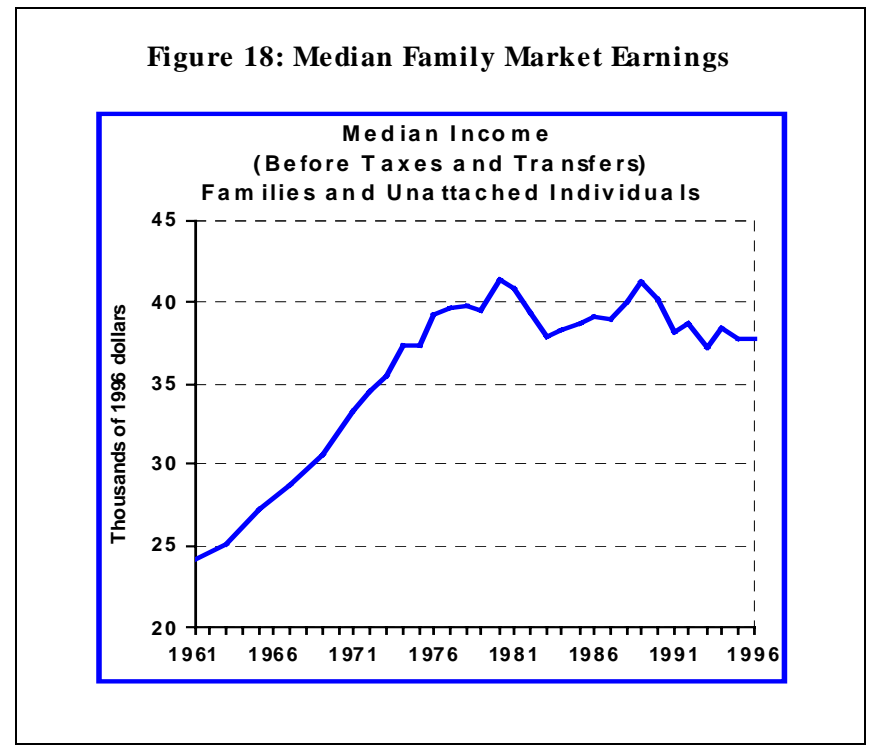




\section{Part B: Distributional Outcomes: Who is Winning and Losing}

Aggregate trends are not necessarily the place to be looking for structural change resulting from shifts in either labour demand or supply. Researchers have been looking at relative earnings, employment and unemployment to assess these possible effects. We start with earnings.

\section{Relative Earnings}

\section{Declining Real Earnings Among Young Workers, Particularly Males}

The real earnings of younger male workers in particular have fallen. Cross-sectional data clearly indicate an increasing earnings gap between younger and older workers, particularly among males, during the 1980s and 1990s (Morissette, Myles and Picot, 1994; Betcherman and Morissette, 1994, Picot, 1998). Real annual earnings of younger men (under 35) working fulltime full year fell through both the recessions of the early 1980s and 1990s, and did not recover during the expansions (Figure 19). Meanwhile, earnings rose among older men further increasing the wage gap.

This might suggest that relative wages among older workers have risen, reflecting a rising wage premium for experience. However, Beaudry and Green (1996) demonstrate that cohort effects account for this apparent relative decline. That is, the earnings of each successive cohort of young male workers entering the labour market have been falling through the 1970s, 1980s, and early 1990s. This represents a downward shift in the age-earnings profile of each successive cohort. This effect would appear like an increase in the relative wages for older workers in crosssectional data, but within any given cohort the relative wages of the younger and older workers have not changed. Wages have fallen for young workers as they enter the labour market, and this decline persists as they age.

This decline in wages is observed for both the more and less highly educated (Kapsalis, Morissette and Picot, 1999). Having a degree did not protect young men from the wage decline, although data from graduates surveys suggest that the deterioration in labour market outcomes for recent male university graduates has been only marginal through the 1990s (Finnie, 1998).

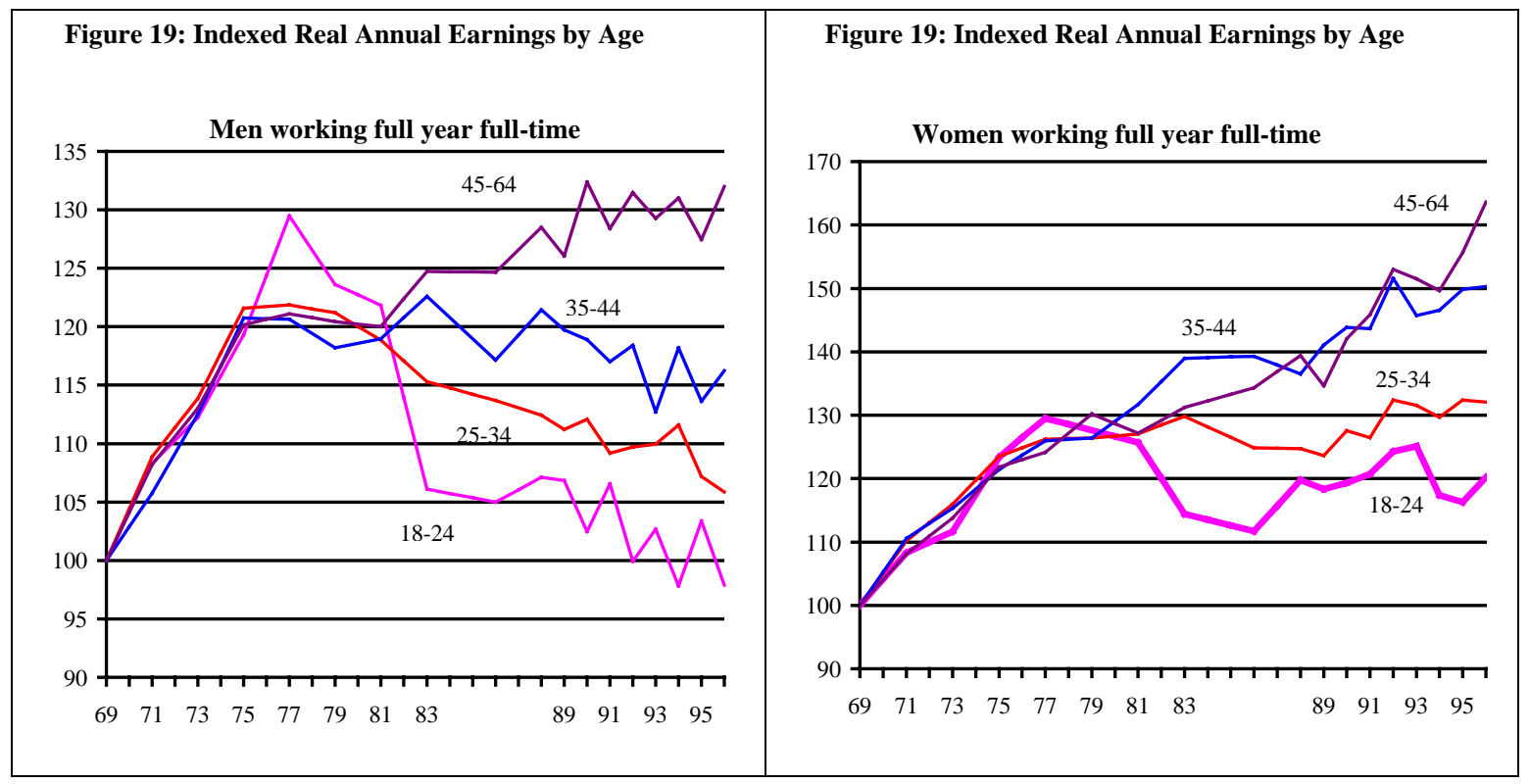


Thus, recent analysis suggests that relative wages between younger and older workers (in the same cohort) have not changed significantly in Canada in the 1990s. However, real earnings among the young, particularly young males, have fallen relative to earlier cohorts.

Little is known regarding the cause of the declining real and relative (to earlier cohorts) earnings of young workers, males in particular. The supply of younger workers has been falling, not increasing, both in absolute terms and relative to the overall supply of labour. The number of 2534 year old males in the labour force fell at $1.3 \%$ per year through the 1990s, while the number of 45-54 year olds increased at 4.1\%. The trends for women were similar (Table 1). This would tend to increase, not reduce relative wages. But there is another dimension of supply-side changes that could explain, in part, some of the changes. The educational attainment of older workers has risen much faster than that of younger workers, with the result that at the top of the educational distribution at least, there is little difference in 1998.

The change in the educational classification system in 1989 makes comparisons difficult. We will focus on the university educated, where changes have if anything reduced the share reporting a degree. In 1981, 16.4\% of younger (25-34) males had a degree, compared to $11.8 \%$ of older males (45-54)...a gap of 4.6 percentage points. By 1995 this gap had disappeared, with the numbers rising to $22.2 \%$ and $22.4 \%$ respectively. Both age groups had become much more highly educated, but the more mature group much more rapidly. ${ }^{13}$ Among women, $16.6 \%$ of younger women held a degree in 1981, compared to 6.9\% of older women. By 1995 this had risen to $25.3 \%$ among the young (higher than for men) and $19.6 \%$ of older women. The gap did not close to the same extent for women, largely because of the dramatic increase in the educational attainment of young women. Kapsalis, Morissette and Picot (1999) conclude that the changing relative educational levels of the young and old accounted for about one-quarter of the rising cross-sectional earnings gap between younger and older workers during the 1980s, and most of it during the 1990s. Declining unionization among younger workers (Morissette, 1998) may also play a role in the falling earnings of the young. To date, however, when attempting to explain changing relative wages, most of the focus has not been on supply-side changes, but rather changes on the demand-side, notably those related to technological change. However, the earnings decline was concentrated among young male workers. Traditionally, they held a significant educational advantage over other workers, notably young women and older men. As will be seen later, (Figure 21) this relative advantage has largely disappeared, no doubt influencing their relative outcomes.

\section{The Labour Market Experiences of Recent Immigrants Resemble Those of Young Labour Force Entrants}

Although we may not understand the underlying cause, more recent cohorts of new and recent labour market entrants, notably workers under 35, are earning less on average than did their earlier counterparts. But young workers are not the only new entrants to the labour market. Recent immigrants also constitute another pool of new entrants. Their earnings experience is very similar to those of recent young entrants: declining real earnings and employment rates for each successive cohort over the 1980s and 1990s, particularly among men. Figure 20 shows the employment and earnings patterns of prime-aged (25-44) university-educated recent immigrants (i.e. those immigrating during the previous five years) in 1986, 1991 and 1996 (thus, age and

13 This rapid increase among middle aged workers no doubt relates to the rapid increase in the university enrollment rates during the 1960s and early 1970s, and the fact that these cohorts are now moving into the 45-54 year old age group. 
education are controlled for in these comparisons). The figures display the results for immigrants who are visible minories, and others. The outcomes for recent immigrants are compared to those of Canadian-born. Among male university graduates, both the share who are employed, and the relative earnings of those employed (relative to all workers) have been falling. For non-visible minorities, the employment/population was $92 \%$ of that of their Canadian counterparts in 1986 , falling to $87 \%$ by 1996 , while their relative earnings fell from 0.85 to 0.70 . The declines for women are evident only in 1996. Compositional changes could influence these results, but it seems unlikely that they would account for them. This particular group (non-visible minority, university educated, 25-44, males) is likely quite comparable through time, with few compositional changes. Just as with new and recent labour force entrants who are young males, those who are immigrants are seeing a similar deterioration in their labour market success (Badets and Howatson-Leo, 1999).

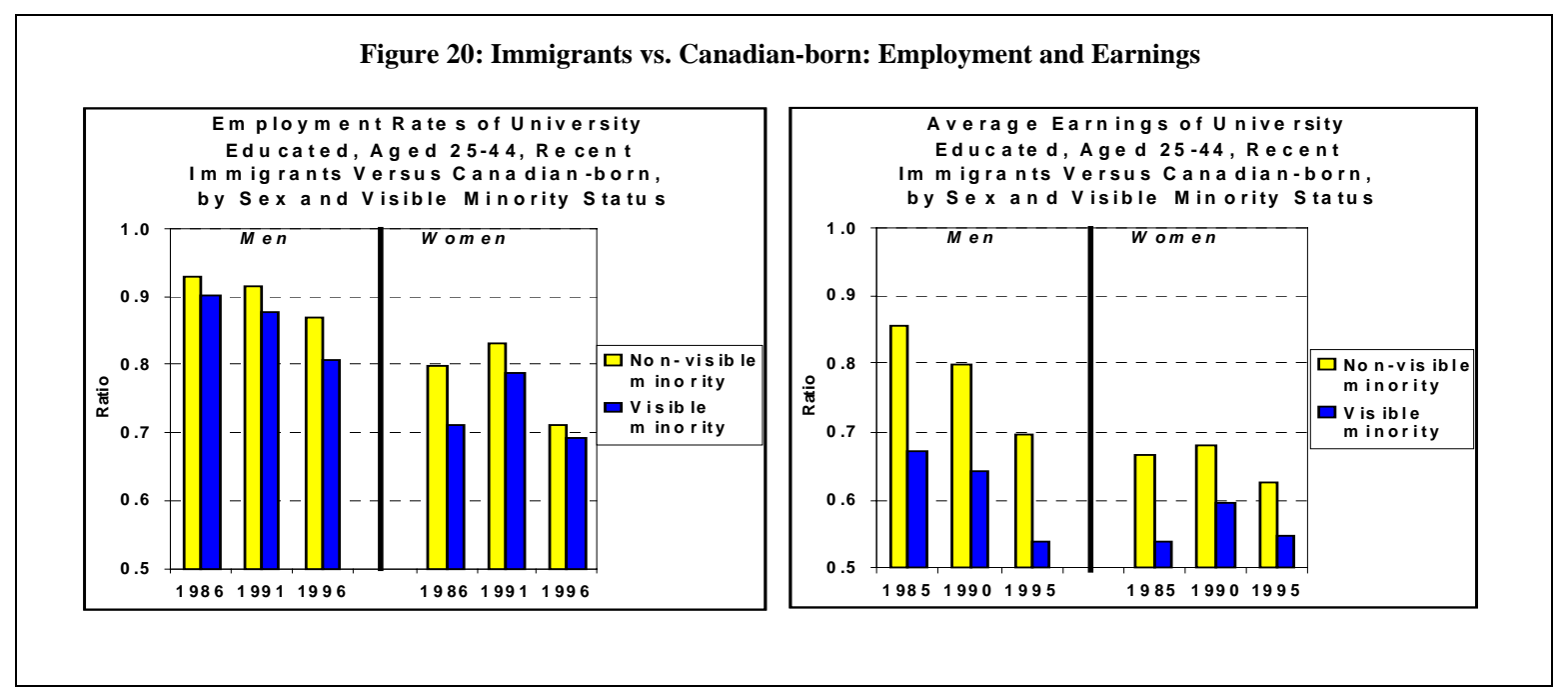

\section{Relative Earnings of the More Highly Educated}

It has been argued by many that increasing technological change has increased the demand for more highly skilled (and experienced) workers. This would result in increasing relative wages (relative to the less skilled) unless supply shifts matched the change in demand. The basic facts suggest that, in Canada, through the 1980s and mid-1990s there was no marked increase in the returns to education. Numerous studies have shown that there has been little or no general increase in relative earnings among the university educated relative to the high school educated through the 1980s and 1990s (Morissette, Myles and Picot, 1994; Bar-Or et. al, 1993; Beach and Slotsve, 1996). The explanation for this stable pattern of relative earnings in Canada, appears to be that the relative supply of highly educated workers increased in Canada at a rate that offset the increase in the relative demand, resulting in little change in their relative labour market status (Freeman and Needels, 1991; Murphy, Riddell and Romer, 1998). Similarly, the relative employment to population ratios of the university to high school educated suggests that there has been no relative gain among the more highly educated in terms of the likelihood of being employed, relative to the high school educated (Sargent, 1999), although there is some evidence that the likelihood of being employed has fallen for those with less than a high school education. Thus, in the aggregate, the relative employment and earnings position of the more highly educated has not risen. This is unlike the U.S., where the wage premium among the more highly educated has risen (Juhn, Murphy and Pierce, 1993; Freeman and Needels, 1991). 


\section{The Role of Technological Change}

There is increasingly a debate regarding the role of technological change in explaining changing relative wages and earnings inequality. A number of influential papers during the early 1990s argued that the increasing earnings premium observed in the U.S for the university educated was a significant part of the story of rising male earnings inequality, and that this was consistent with the notion of an increasing demand for highly skilled labour being driven by technological change (Juhn, Murphy and Pierce, 1993; Katz and Murphy, 1992; Bound and Johnston, 1992). Similar demand side changes are seen to be at work in Canada, but offset by supply side shifts, hence attenuating inequality increases and changing relative wages by education. But is technological change the primary driving force behind such changes? Some argue the role of technological change may have been overstated.

Earnings inequality in Canada has risen and continues to rise among men, but has changed little among women (Picot, 1998). The OECD (1998) asks how one can reconcile this with technological change, which is presumably continuing into the 1990s, and should affect women as well as men. Fortin and Lemieux (1997) argue that institutional factors such as a declining real minimum wage, declining unionization, and deregulation were important determinants of rising wage inequality in the U.S. In Canada, increasing returns to experience (and skill associated with experience) have not really taken place, as argued by Beaudry and Green (1996), and hence the argument that increasing wage premiums for experience is consistent with the effects of technological change (Davis, 1992) holds little validity. And why have earnings of young males, including those university educated, been falling if technological change in the shift to the knowledge-based economy were boosting demand for skilled labour? It is among the young that computer-related skills are the highest.

Reviews by David Green for the OECD (1998) and Sargent (1999) argue that the changes in labour market outcomes and industrial structure that prevailed in the 1990s are not necessarily the ones that one might expect to see in an economy where technological change was driving structural change. Changes in information technology have clearly had an impact on labour market outcomes for workers, and such change is part of the evolution of the 1990s labour market. But there are important phenomenon that cannot be explained and are at times inconsistent with the belief that technology is the sole, or perhaps even primary, driving force. The debate regarding the role of technological change will no doubt continue.

\section{The Shifting Relative Labour Market Position of Men and Women}

The changing relative position of women and men is one of the most significant labour market phenomena of the 1990s, and it has not received the attention it deserves. Among the recent supply-side shifts is the increasing educational attainment of women, both in real terms, and perhaps more significantly, relative to men. For example, between 1976 and 1998 female labour force members with a university degree were increasing at $7.6 \%$ per year, compared to $4.2 \%$ for men. The result is that the gap between men and women regarding the share holding degrees disappeared by 1998 (Figure 21 and Table 2). In fact, the educational advantage held by young men (over younger women and older men) in 1976 had more than disappeared by 1998 at which time a larger share of young (25-34) women than men held degrees (Figure 21). 
Since human capital is a major determinant of labour market outcomes, it should not be too surprising that the relative earnings, employment and unemployment of women are improving. However, there are likely other factors at play. As noted in an earlier section, even after controlling for change in human capital characteristics (education and age), employment and unemployment outcomes deteriorated for men, but not for highly educated women, and relatively little for other women. And as will be shown below, even after controlling for broad education and age (experience) levels, womens' earnings rose faster than mens' during the first half of the 1990s.

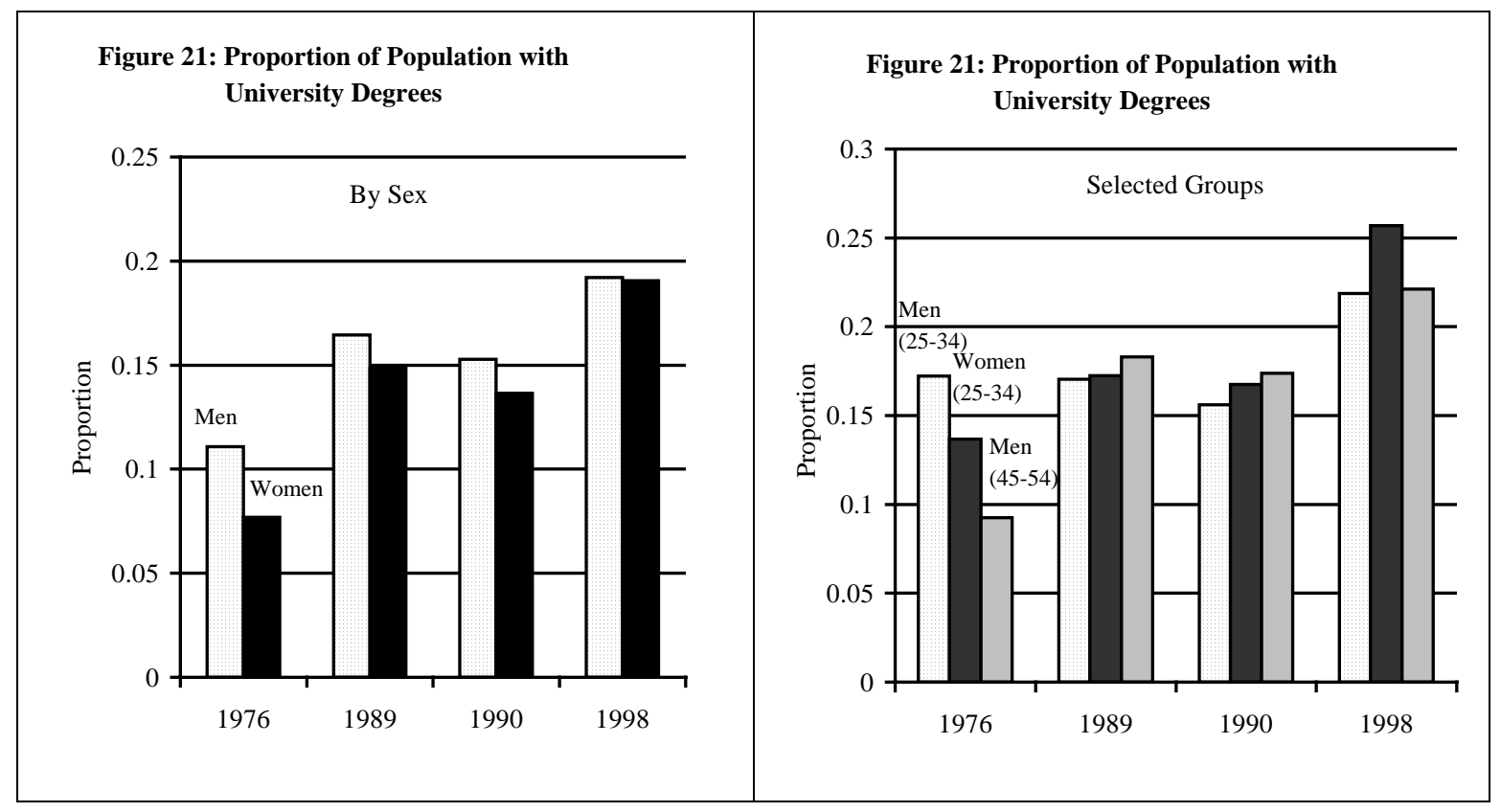

\section{Earnings}

While aggregate data indicate than women continue to earn less than men, the gap has been narrowing. The weekly earnings of female full-time workers ${ }^{14}$ displayed a significant increase in the 1990s compared to the 1980s (Figure 22), rising 12\% between 1989 and 1996 . Weekly earnings fell marginally among comparable male workers. Controlling for age, education, fulltime, part-time states and industry, produces much the same results. Kapsalis, Morissette and Picot (1999) ran wage equations for men and women (separately) in different age groups. They then computed expected weekly earnings.

14 From the Survey of Consumer Finances. 

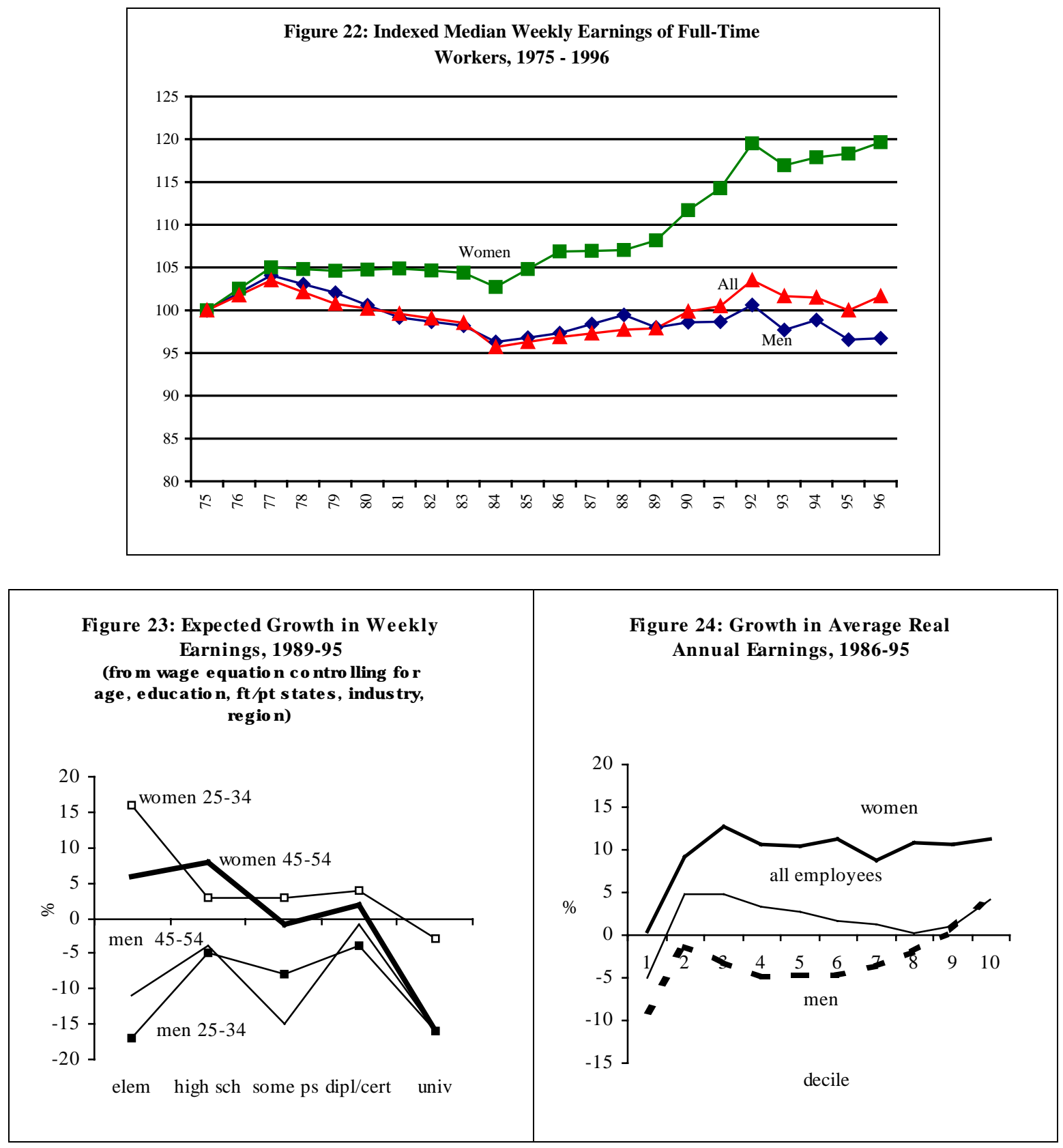

During 1989-95 period, the growth in expected weekly earnings (controlling for industry, region, and full-time/part-time status) was greater for women than men across all levels of education (except for the university educated), and in the younger and older age groups (Figure 23). Basically, mens' weekly earnings were declining, womens' were rising. Evidence based on annual earnings supports this, and suggests this phenomenon is independent of where in the earnings distribution one is located. The growth in annual earnings of women has far outstripped that of men across the entire earnings distribution (Figure 24). Between 1986 and 1995, two years in roughly comparable positions in the business cycle, womens' annual earnings rose $10.6 \%$, and mens' fell by $1 \%$. Except for women at the very bottom of the earnings distribution (where earnings rose by only $0.4 \%$ ), earnings growth was between $9 \%$ and $11 \%$. Men's earnings fell across the entire earnings distribution, except among those in the top two deciles, where there were earnings gains (Figure 24). 
There are numerous possible reasons for these phenomena. Women are moving into higher paid occupations and fields of study at an increasing rate, and such effects would not necessarily be controlled for in the broad type of controls used here. Using the longitudinal data from the National Graduates Survey, Finnie and Wannell (1999) find that the wage gap has been narrowing for male and female graduates, and that the higher the education level, the lower the gap. For the latest cohort of graduates in their study (1990), the male/female wage gap for doctoral graduates had disappeared, at least during the five years following graduation.

\section{Employment Indicators Among Prime Aged Men and Women}

Earnings growth was largely positive for women and negative for men in the 1990s. Is this reflected in employment and unemployment outcomes? There may be special conditions influencing the outcomes of younger workers (changing employment patterns among students) and older workers (increasing early retirements) which could affect the relative change between men and women. Hence, we focus on prime aged workers, aged 25-54. Labour force statistics suggest that the position of prime aged men has deteriorated between the late 1980s and 1990s, while that of women has improved. We calculated average rates for the 1986-88 period, and compared them to average rates for the 1996-98 period. Both periods are roughly an equal number of years into the recovery. Labour force participation fell for men (by $2.9 \%$...not percentage points), and rose for women $(6.7 \%)$ (Table 4$)$. The unemployment rate rose for men $(13 \%)$ and fell for women $(6 \%)$, so that while unemployment was higher among women than men during the 1980s, by the late 1990s this was reversed. The employment/population ratio fell for men (4\%) and rose for women (7\%). The one statistic which was negative regarding women relates to unemployment duration, which rose by $10 \%$ among women, and declined marginally among men $(2 \%)$. These changes were more than offset by increases in the incidence of unemployment among men, and declines among women (by 15\%).

\begin{tabular}{|c|c|c|c|c|c|}
\hline \multicolumn{6}{|c|}{ Table 4: Labour Force Statistics - 25-54 Year Olds Only } \\
\hline & & $1986-88$ & 1996-98 & $\%$ change & difference \\
\hline \multirow[t]{3}{*}{ Labour Force Participation Rate } & All & 82.9 & 83.9 & 1.2 & 1.0 \\
\hline & Men & 93.8 & 91.1 & -2.9 & -2.7 \\
\hline & Women & 72.0 & 76.8 & 6.7 & 4.8 \\
\hline \multirow[t]{3}{*}{ Unemployment Rate } & All & 7.6 & 7.9 & 4.0 & 0.3 \\
\hline & Men & 7.1 & 8.0 & 12.9 & 0.9 \\
\hline & Women & 8.3 & 7.8 & -5.8 & -0.5 \\
\hline \multirow[t]{4}{*}{ Employment/Population Ratio } & All & 76.6 & 77.3 & 0.9 & 0.7 \\
\hline & Men & 87.2 & 83.9 & -3.8 & -3.3 \\
\hline & Women & 66.0 & 70.7 & 7.2 & 4.8 \\
\hline & & 1984-86 & 1994-96 & $\%$ change & Difference \\
\hline \multirow[t]{3}{*}{ Inflows to Unemployment* } & All & 1.95 & 1.86 & -4.4 & -0.1 \\
\hline & Men & 1.73 & 1.83 & 6.0 & 0.1 \\
\hline & Women & 2.25 & 1.89 & -15.7 & -0.4 \\
\hline \multirow[t]{3}{*}{ Duration of Unemployment (Months)* } & All & 4.1 & 4.2 & 2.6 & 0.1 \\
\hline & Men & 4.4 & 4.3 & -2.1 & -0.1 \\
\hline & Women & 3.7 & 4.1 & 10.4 & 0.4 \\
\hline
\end{tabular}

* Inflows to and duration of unemployment compare 1984-86 with 1994-96. 
There are certainly many reasons for this change in relative labour market position, including changes in the types of jobs held by women, and the industries in which they work. However, relatively little is known regarding these relative shifts in earnings, employment and unemployment, and this remains one area requiring further research.

\section{Earnings I nequality and Low-Income}

While earnings inequality rose during the 1980s, particularly among men (Beach and Slotsve, 1996), there is evidence that earnings inequality among all employed individuals (men and women combined) changed little between the mid-1980s and 1990s (although it rose for men and was stable among women) (OECD, 1998; Wolfson and Murphy, 1998; Picot, 1998). However, among families, inequality in market earnings has risen substantially (Figure 25). From a welfare perspective, this is perhaps the more useful measure. Inequality in family market earnings rose in part because of compositional changes, notably the rise in lone-parent families, and the fact that men and women with similar earnings levels are increasingly marrying one another (Zyblock, 1997).

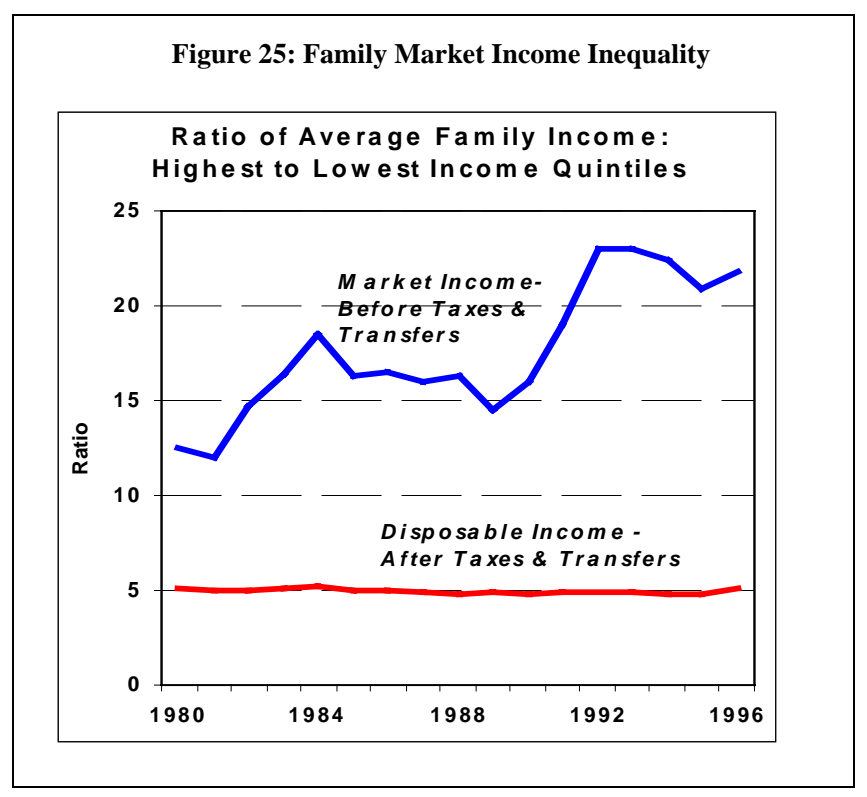

With rising family market earnings inequality, and cutbacks to the transfers in the mid-1990s, both the low-income rate and gap increased in the 1990s. This is a significant deviation from the 1980s. With the rising level of government transfers to low-income families through the 1980s and early 1990s, the rate of low-income did not rise (except for cyclical variation). By the mid1990s, however, as the transfer system was being reformed and transfers reduced in some provinces, the low-income rate increased (Figure 26). It was 36\% higher in 1996 than in 1989 (0.136 vs. 0.100$)$. 


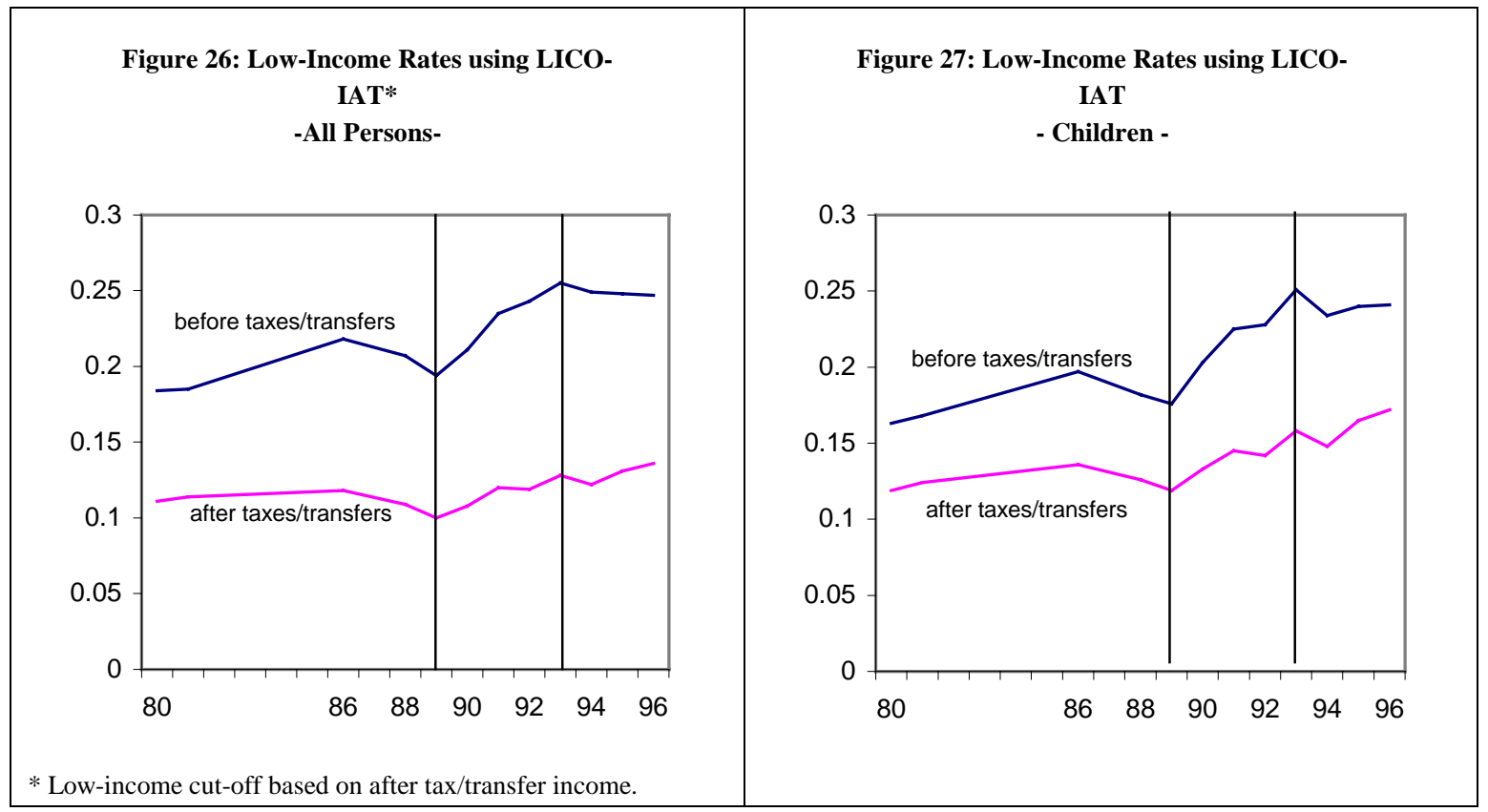

These trends are even more striking among low-income families with children, currently a high priority for the federal government (Figure 27). Significant declines in employment earnings through the 1980s and early 1990s occurred simultaneously with two kinds of adjustments: families adjusted their lifestyle to reduce low-income (i.e. fewer children, having children later, more working wives, higher education levels) and per family transfer payments rose steadily (Picot and Myles, 1996). Through the 1980s and 1990s, the source of income for low-income families with children displayed dramatic change: employment earnings declined, and lowincome families became much more dependent on transfers, notably social assistance. In the 1970s, earnings accounted for two-thirds of their family income, transfers one-third. By the 1990s this was reversed; social transfers accounted for two-thirds of family incomes, employment earnings one-third (Figure 28). By the mid-1990s, however, adjustments in family characteristics had ceased to put downward pressure on the low-income rate (i.e. the number of two-earner families was if anything declining, the number of children per family was stable, as was educational attainment of families) and transfers were cut back faster than employment earnings rose (Picot and Myles, 1998). In this environment, the low-income rate (and low-income intensity which is the change in the low-income rate and the low-income gap combined) have increased significantly. In 1996, low-income intensity among children was $28 \%$ above the highest level observed during the recession, and 55\% above the value at the last business cycle peak (1989). 


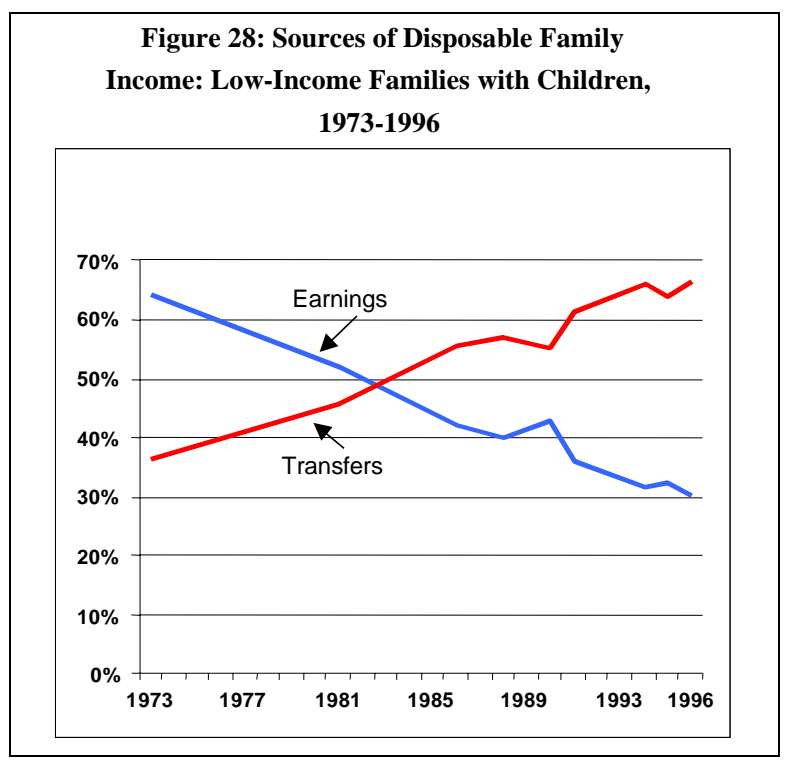

\section{Part C: Summary of Findings and Discussion}

While there was a remarkable shift in job creation during the 1990s from full-time paid jobs to own account self-employment, there is too little available research to assess whether this is an enduring change in the nature of work in Canada. It may be a reaction to the very slack labour market of the 1990s, or it may be driven by a number of "institutional" causes (e.g. personal and payroll taxes) discussed in the paper along with compositional shifts in the labour force. Consistent with very low rates of full-time job creation, participation rates have fallen (among the young in particular). And with the suppressed participation, unemployment fell at about the same rate during the 1990s recovery as the 1980s. Furthermore, there was little increase in the incidence or duration of unemployment spells. There is little evidence of the "ratcheting up" of unemployment during the 1990s compared to the 1980s cycle that is often referred to in discussions of the 1990s. But by historical standards it remained very high during both periods.

The story regarding labour flows appears to be straightforward. Employers response to low employment growth appeared to be more on the hiring than layoff side, as hiring rates were low during the 1990s, but the likelihood of permanent layoff was no higher than during the 1980s. Consistent with poor job opportunities, quit rates were low, which meant that labour mobility actually declined in the 1990 s as compared to the 1980s. The reallocation of labour among companies due to structural change or because of inter-firm competition was lower during the 1990s than 1980s recovery. There is little support here for a notion of rapid structural change in which workers are reallocated and displaced at increasing rates. Others have also found little evidence of rising industrial structural change (Gera and Mang, 1997; Sargent, 1999).

With a lower probability of a worker separating from their firm comes increased average job tenure, in spite of concerns regarding job stability during the 1990s. This is not necessarily a positive outcome, however, as it is driven to a great extent by the weak job market and the lower quit rate.

There is evidence from the job destruction data that company downsizing during the recovery period was greater in the 1990s than the 1980s. This higher level of job destruction played a role in the slow employment growth. However, much of this increased job destruction was located in 
the public and consumer services sectors. This is not completely consistent with the notion that increased competition (often international) or technological change was driving commercial firms to downsize to a greater extent. One might have expected to see more evidence of this change across the entire commercial economy.

The latest productivity data from Statistics Canada suggests productivity growth in the 1990s was very similar to that seen since the slowdown of the 1970s. One does not see a rapid increase driven by increased use of information technologies of other changes in firms. However, one also does not see a continuous deterioration in productivity growth over the 1980s and 1990s. The growth in income of Canadians as measured by GDP/capita did slow in the 1990s, in large part because of the low growth in the proportion of Canadians working. Median family earnings also showed no improvement in the 1990s.

However, the above macro-level results do not take into account important supply-side shifts, notably the increase in the quality of the Canadian labour force. When focusing on changes in macro-level trends for a representative worker with a fixed level of education and experience, we find substantial deterioration in the labour market of the 1990s. After controlling for education and experience (age), labour force participation falls by 5 percentage points between the late 1980s and 1990s, unemployment increases 2 percentage points, and the likelihood of being employed in paid work falls by 5 percentage points. In an absolute sense, the expected labour market outcomes for a worker with a given level of human capital have fallen during the 1990s, particularly among males. But what of relative positions. Part II of the paper deals with distributional outcomes.

One of the most striking outcomes of the 1990s labour market was the improvement for women and deterioration for men, particularly young men. It is likely that the improvement in the education level of women is associated with these results. But there are other possible factors about which little is known. While earnings inequality of all workers (men and women) increased little between the mid-1980s and 1990s, inequality of family market earnings rose substantially. When combined with the reductions in transfer payments in the mid-1990s, the low-income rate is seen to increase between 1993 and 1996 in spite of the slow economic recovery. This trend was particularly strong among children, and a significant deviation from the 1980s.

In spite of the notion of a shift to the "knowledge-based economy", it has been known for some time that there has not been an increase in the wage premium for the more highly educated in Canada, unlike the U.S. Research suggests this is due to the rapid increase in the relative supply of the highly educated in Canada.

Youth earnings have fallen, however, particularly among men. Research suggests this is a potentially permanent downward shift in the age-earnings profile of recent cohorts of new labour force entrants. That is, a potential reduction in recent cohorts' (through the 1980s and 1990s) lifetime earnings and standard of living. But young males are not the only group of new labour force entrants to face this deterioration in earnings. Recent immigrants, again particularly males, face a similar situation. The causes of this deterioration in the labour market for recent entrants is not well understood. Little research has been done to find underlying causes. While technological change may play a significant role in some of the changing distributional outcomes, research is increasingly questioning whether this is the only, or even primary driving force. The supply side shifts, particularly regarding educational attainment have been dramatic. In particular, the 
educational advantage that young male workers not so long ago held over both young female workers and more mature workers has largely disappeared. Given the importance of education in determining labour market outcomes, this may in part explain the declining relative position of young males. Further research of potential causes is needed.

The performance of the 1990s labour market was significantly different than that of the 1980s. One could tell the following story. In a prolonged weak recovery, firms apparently turned to decreased hiring rather than increased layoffs to adjust. With a low hiring rate, the participation rate was depressed, particularly among the young. With high labour market slack, selfemployment increases as workers choose to create their own jobs. Quit rates fall in the face of poor job opportunities, and labour mobility slowed. This increases job tenure among the employed. The often discussed downsizing appeared to play a role in the slow unemployment growth, as it was higher in the 1990s than the 1980s. This version of the story suggests that the weak recovery played a major role in the changes in labour market outcomes between the two decades. This could also have prompted firms to change their behaviour in a more enduring manner, however, resulting in long-term structural shifts. In this case, the nature of work would have changed in a "structural" sense.

Regarding the distributional trends, the major ones are the falling real wages young males, the general improvement in the relative position of women to men, and the rising rate of low-income (and rising family earnings inequality). It is not clear that technological change can explain any of these trends. They may have more to do with shifts in relative supply (by educational attainment), and institutional changes such as changing unionization rates and the changing social transfer system.

As noted in the introduction, there are a range of possible causes for the labour market outcomes of the 1990s. Finding answers as to "why" is an on-going process, and there appear to be a number of major puzzles regarding recent labour market outcomes. 

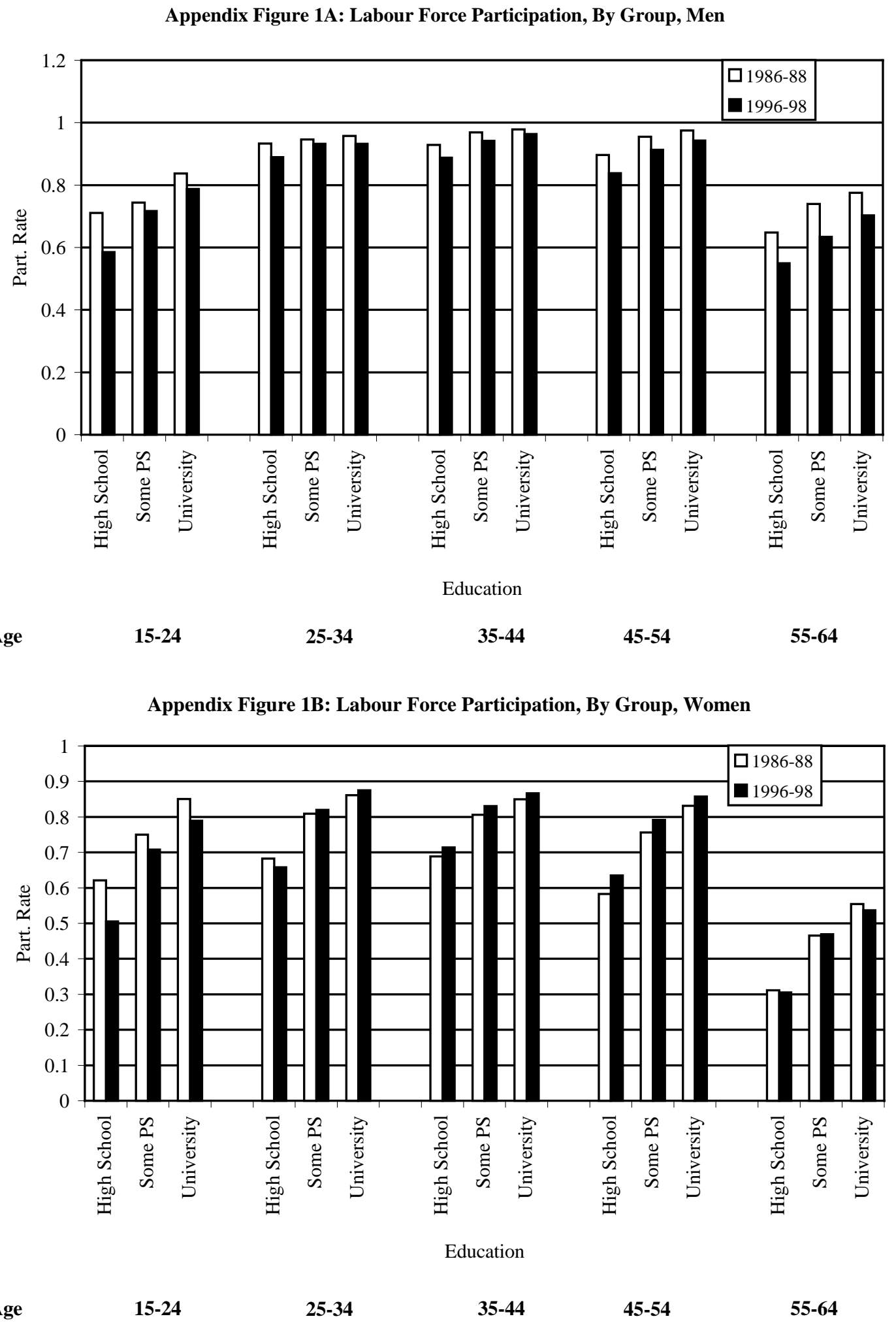
Appendix Figure 2A: Paid Employment Rate, By Group, Men

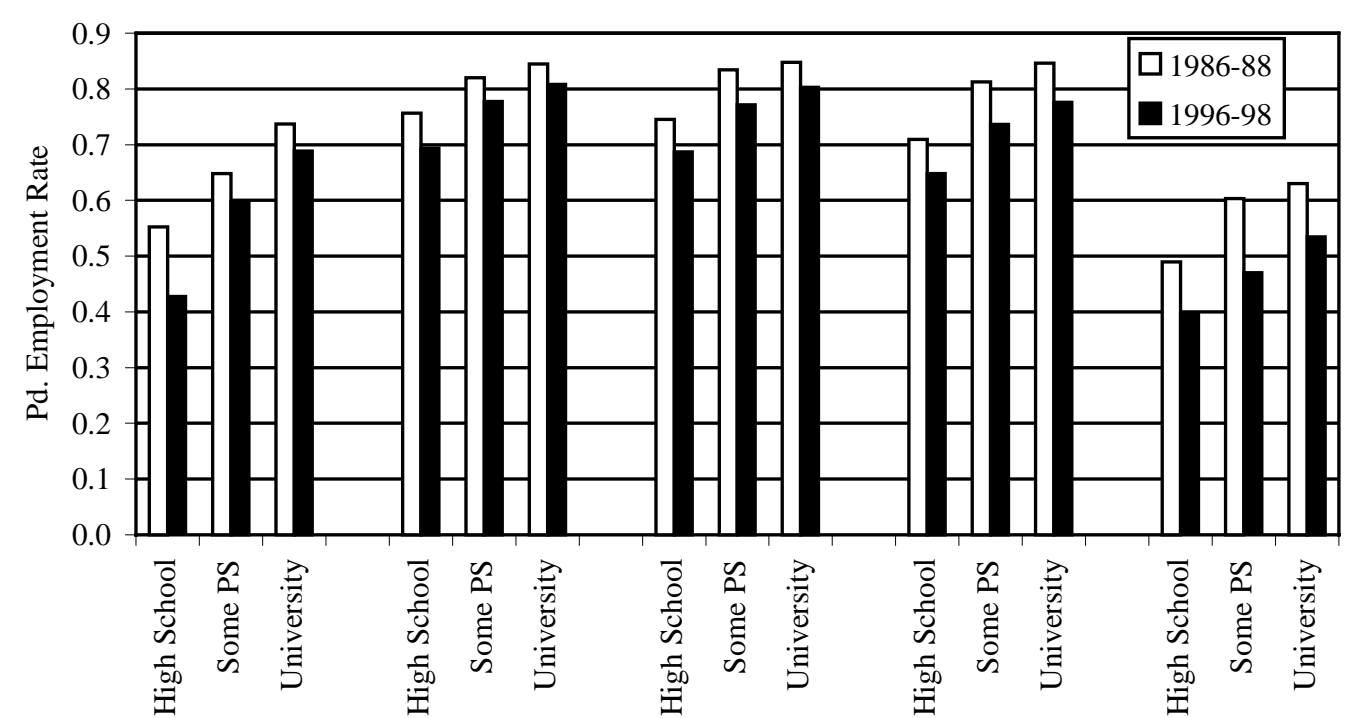

Education

Age

15-24

25-34

$35-44$

45-54

55-64

Appendix Figure 2B: Paid Employment Rate, By Group, Women

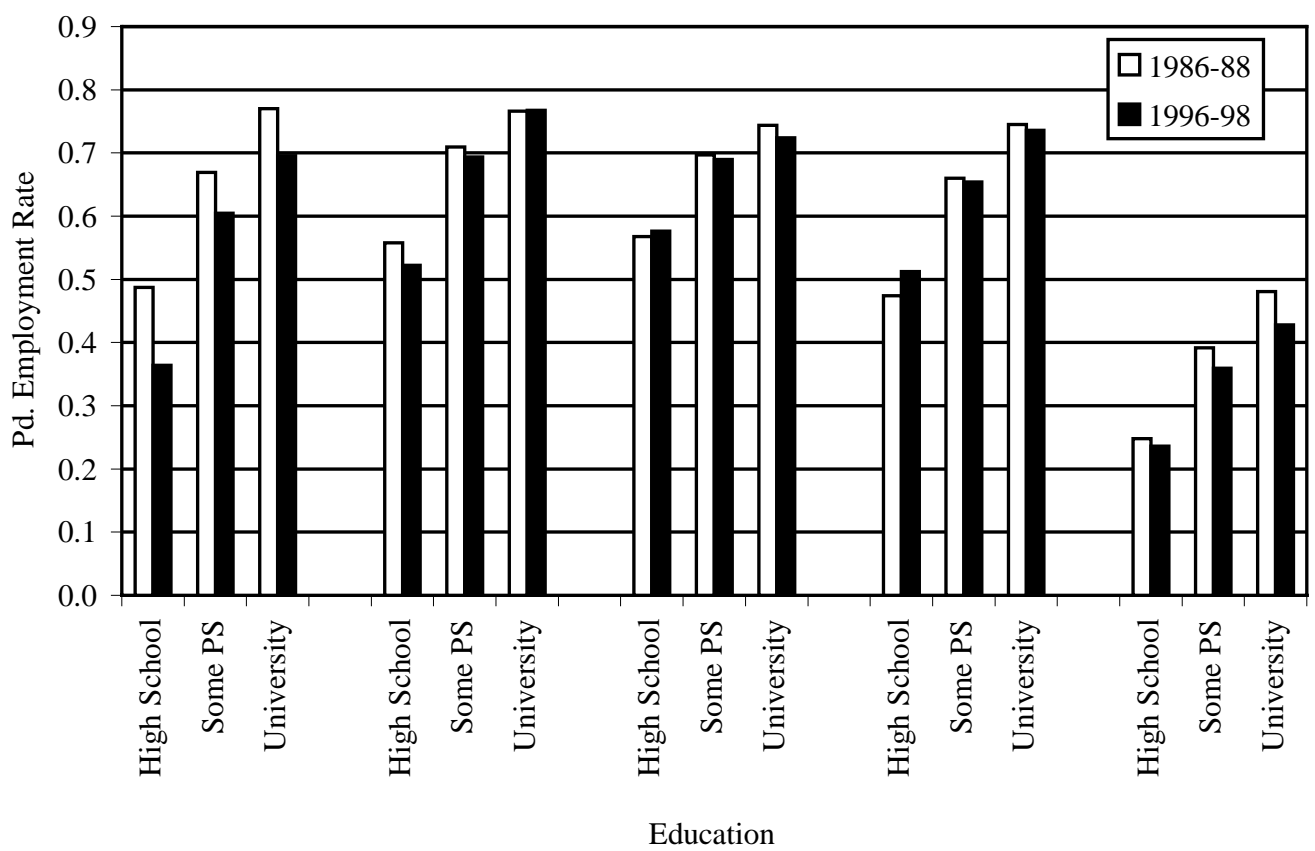

Age

15-24

25-34

35-44

45-54

55-64 
Appendix Figure 3A: Unemployment Rate, By Group, Men

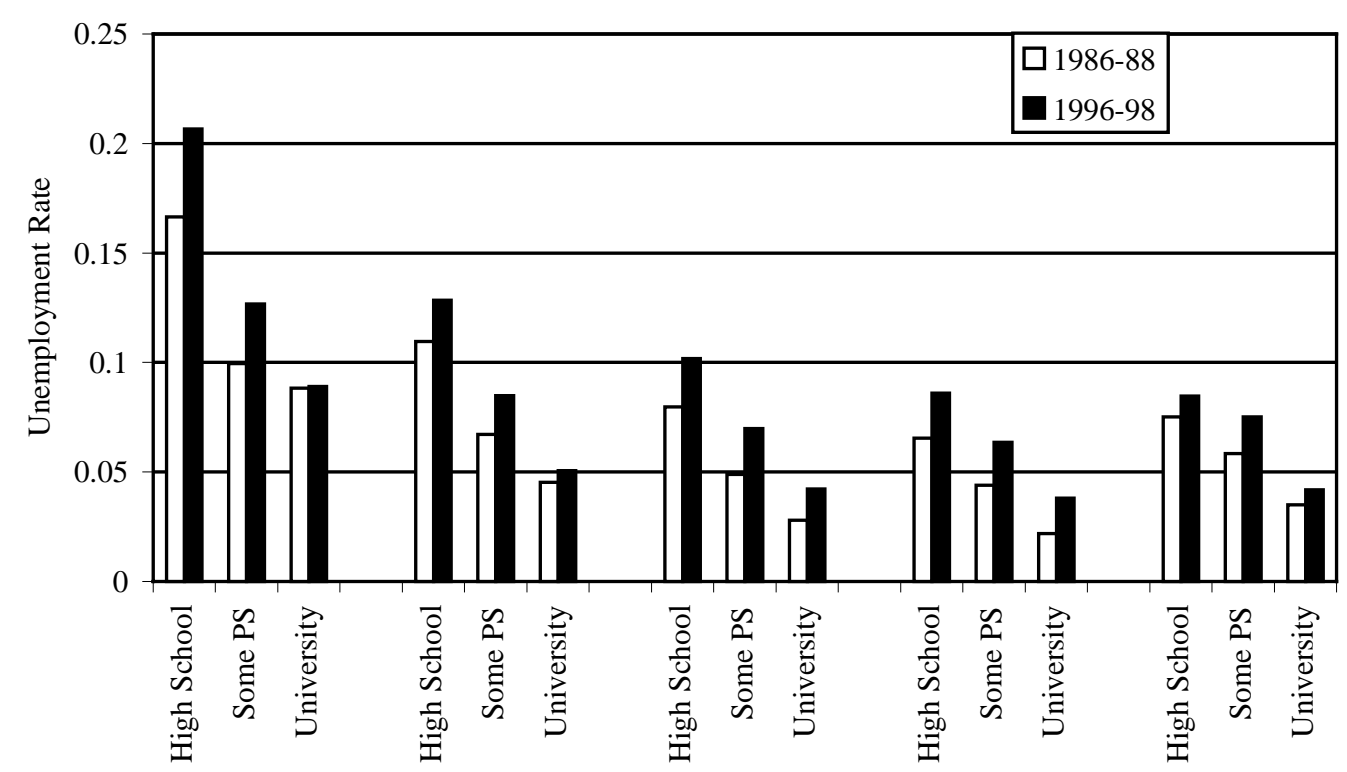

Education

Age

15-24

25-34

$35-44$

45-54

$55-64$

Appendix Figure 3B: Unemployment Rate, By Group, Women

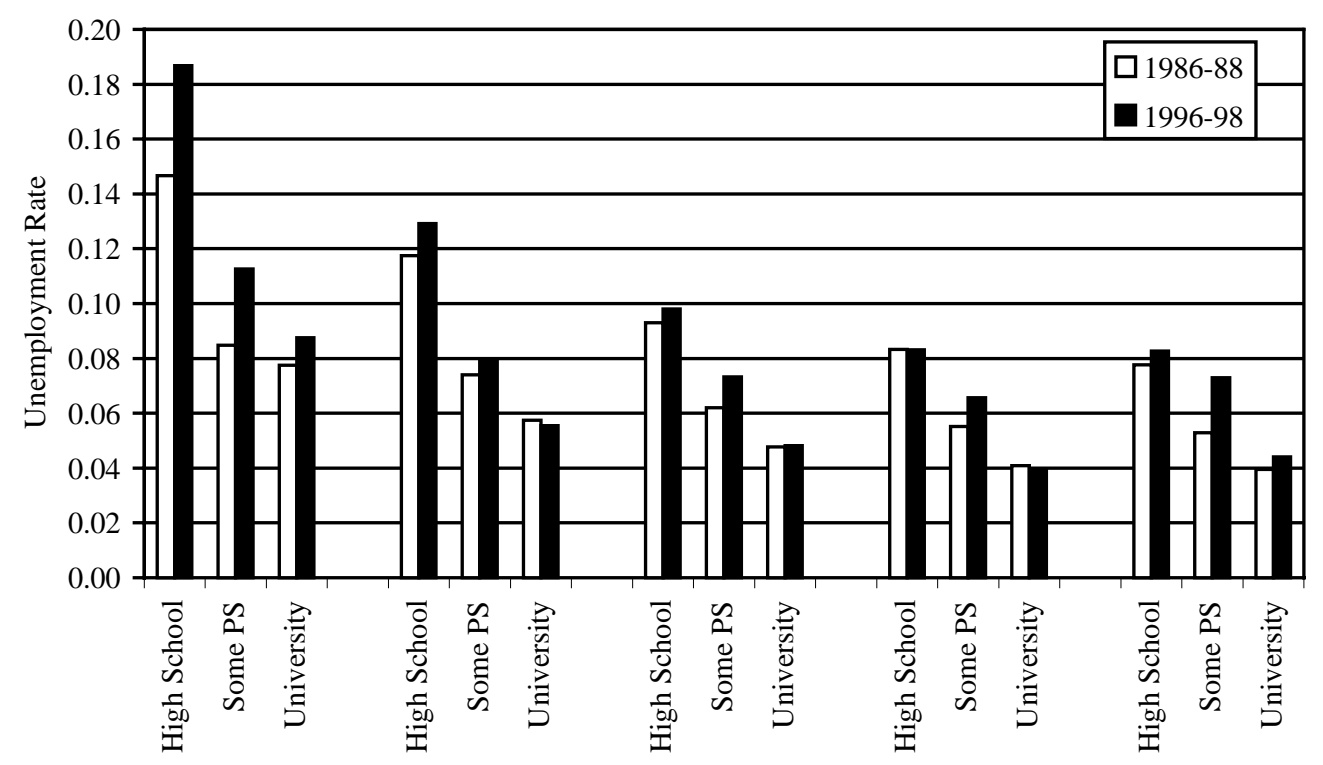

Education

Age

15-24

25-34

$35-44$

45-54

55-64 
Appendix Figure 4A: Unemployment Dynamics, Incidence of Unemployment, By Group, Men

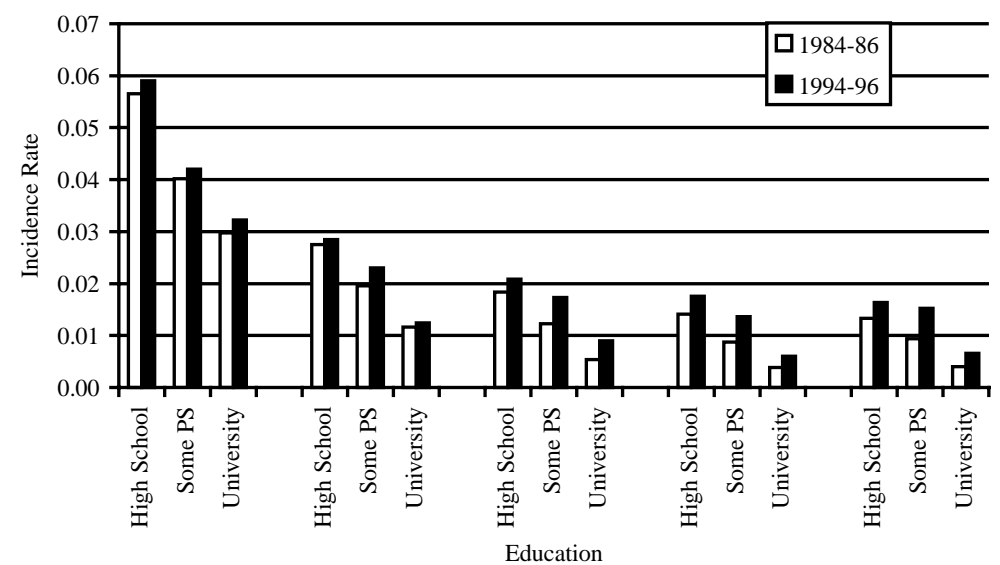

Age

$\begin{array}{lllll}15-24 & 25-34 & 35-44 & 45-54 & 55-64\end{array}$

Appendix Figure 4C: Unemployment Dynamics, Duration of Unemployment, By Group, Men

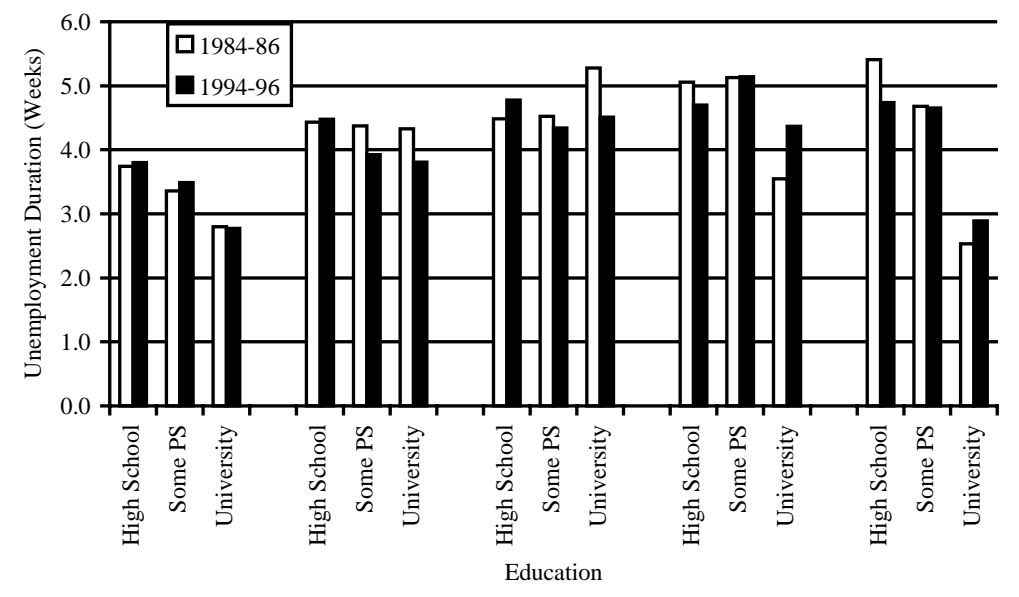

Age

15-24

25-34

$35-44$

45-54

55-64
Appendix Figure 4B: Unemployment Dynamics, Incidence of Unemployment, By Group, Women

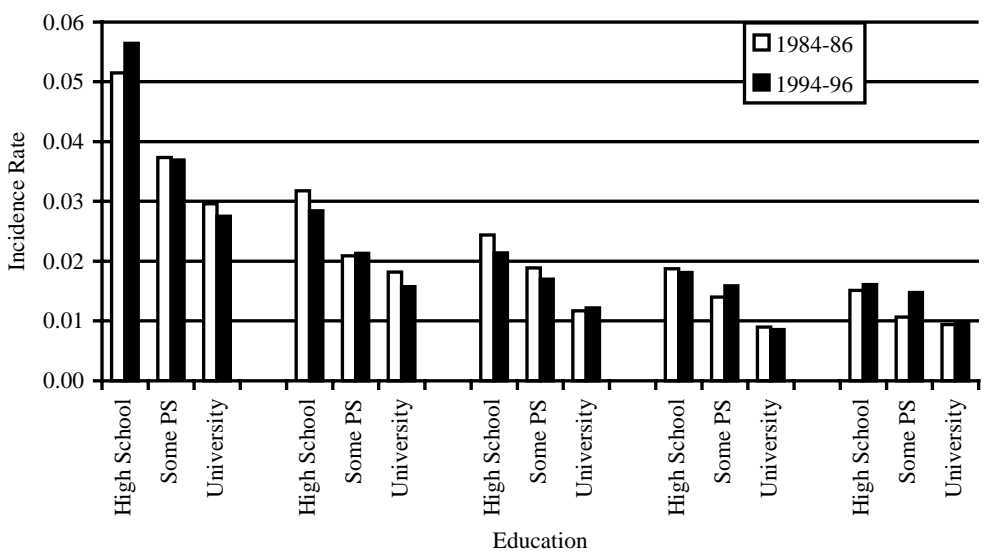

Age

15-24

35-44

$45-54 \quad 55-64$

Appendix Figure 4D: Unemployment Dynamics, Duration of Unemployment, By Group, Women

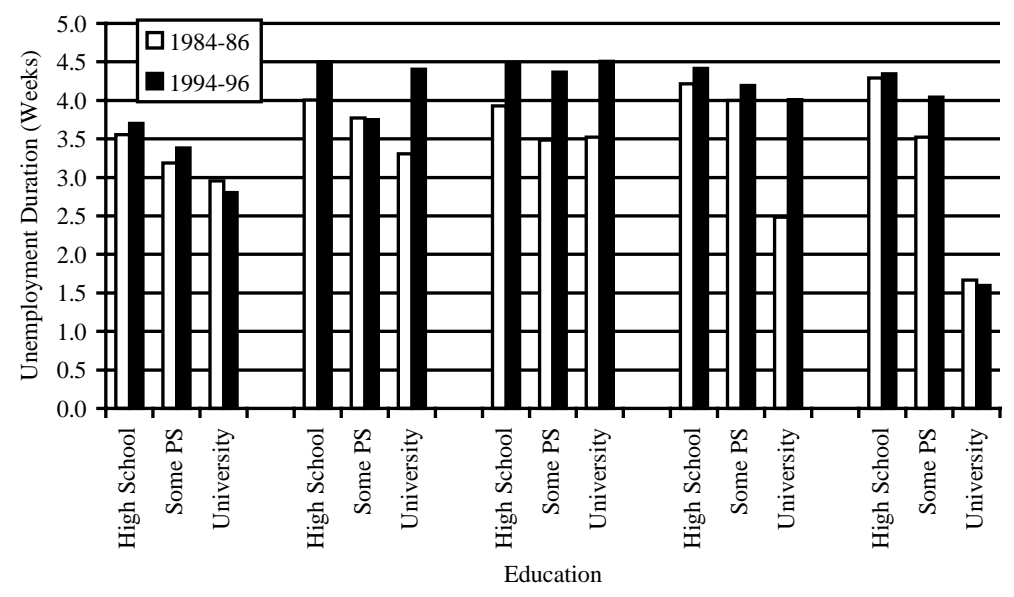

Age

$15-24$

25-34

$\quad \mathbf{3 5 - 4 4 - 5 4}$

$55-64$ 


\section{References}

Badets, Jane and Linda Howatson-Leo (1999). "Recent Immigrants in the Work Force", Canadian Social Trends, Spring, No. 52, Statistics Canada, Catalogue No. 11-008-XPE.

Baldwin, John, Timothy Dunne and John Haltiwanger (1994). "A Comparison of Job Creation and Job Destruction in Canada and the United States". Analytical Studies Branch Research Paper Series, Statistics Canada, No. 64.

Baldwin, John and Stewart Wells (1999). Notes referred to as "Productivity Puzzles", mimeo, Micro-Economic Analysis Division, Statistics Canada.

Bar-Or, Y., J. Burbidge, L. Magee and L. Robb (1993). "Canadian Experience-Earnings Profiles and the Return to Education in Canada, 1971-1990." Working Paper No. 93-04, Department of Economics, McMaster University (Hamilton).

Beach, C. M. and G. A. Slotsve (1996). Are We Becoming Two Societies. C.D. Howe Institute, Toronto.

Beaudry, P. and D. Green (1996). "Cohort Patterns in Canadian Earnings and the Skill Biased Technical Change Hypothesis." Discussion Paper No. 97-03, Dept. of Economics, University of British Columbia.

Betcherman, Gordon and Graham S. Lowe (1997). "The Future of Work: A Synthesis Report," Canadian Policy Research Network, Ottawa, Canada.

Betcherman, Gordon and Kathryn McMullen (1986). "Working With Technology: A Survey of Automation in Canada", Minister of Supply and Services, Canada.

Betcherman, Gordon and R. Morissette (1994). "Recent Youth Labour Market Experiences in Canada.” Analytical Studies Branch Research Paper Series, Statistics Canada, No. 63.

Birch, D. L. (1987). Job Creation in America. New York: The Free Press.

Blanchflower, D. G. and A. J. Oswald (1998). "What Makes an Entrepreneur?" Journal of Labor Economics, 16 (1), 26-60.

Bound, J. and G. Johnston (1992). "Changes in the Structure of Wages in the 1980s: an Evaluation of Alternative Explanations." American Economic Review.

Corak, Miles and Andrew Heisz (1996). "Alternative Measures of the Average Duration of Unemployment," Review of Income and Wealth, 42 (1), pp. 63-74.

Davis, S. J. (1992). "Cross-Country Patterns of Change in Relative Wages." National Bureau of Economic Research Working Paper No. 4085.

Davis, S., J. Haltiwanger and Scott Schuh (1993). "Job Creation and Destruction", MIT Press, Cambridge, Mass. 
Finnie, Ross (1997). "Stasis and Change: Trends in Earnings Levels and Inequality, 1982-92" Canadian Business Economics, Vol. 5, No. 4, pp.84-107.

Finnie, Ross (1998). "Holding Their Own: Recent Trends in Employment Rates and Earnings Levels of Post-Secondary Graduates, Statistics Canada and Schools of Policy Studies, Queens University, mimeo.

Finnie, Ross and Ted Wannell (1999). "The Evolution of the Gender Earnings Gap Amongst Canadian University Graduates", Business and Labour Market Analysis, Statistics Canada, unpublished manuscript.

Fortin, Nicole M. and Thomas Lemieux (1997). "Institutional Changes and Rising Wage Inequality: Is There a Linkage?" Journal of Economic Perspectives 11(2), pp. 75-96.

Freeman, R. B. and K. Needels (1991). "Skill Differentials in Canada in an Era of Rising Labor Market Inequality.” National Bureau of Economic Research Working Paper No. 3827.

Gera, S. and Kurt Mang (1997). "The Knowledge-based Economy: Shifts in Industrial Output," Industry Canada Working Paper No. 15.

Green, David and W. Craig Riddell (1996). "Job Durations in Canada: Is Long Term Employment Declining?" University of British Columbia Centre for Research on Economic and Social Policy, Discussion Paper No. 96-19.

Heisz, Andrew (1999). "Changes in Job Duration on Canada.” Industrial Relations, 54 (2).

Jennings, Phillip (1997). "What Explains the Declining Youth Participation Rate?" Applied Research Branch, Strategic Policy, Human Resources Development Canada, Working Paper W-97-6E, Ottawa.

Juhn, C., K. M. Murphy and B. Pierce (1993). "Wage Inequality and the Rise in Returns to Skill,” Journal of Political Economy 101 (3), pp.410-442.

Kapsalis, C., R. Morissette and G. Picot (1999). "The Return to Education and the Increasing Wage Gap Between Young and Older Workers." Analytical Studies Branch Research Paper Series, Statistics Canada, No. 131.

Katz, Lawrence F. and Kevin M. Murphy (1992). "Changes in Relative Wages 1963-1987: Supply and Demand Factors," Quarterly Journal of Economics CVII (1), pp. 35-78.

Leonard, J. S. (1987). "In the Wrong Place at the Wrong Time: The Extent of Frictional and Structural Unemployment," in K. Lang and J. Leonard (eds.) Unemployment and the Structure of Labor Markets. Oxford: Blackwell.

Lin, Zhengxi, Garnett Picot and Janice Yates (1999). "Rising Self-Employment in the Midst of High Unemployment: An Empirical Analysis of Recent Developments in Canada," Analytical Studies Branch Research Paper Series, Statistics Canada, No. 133. 
Morissette, R., J. Myles and G. Picot (1994). "Earnings Inequality and the Distribution of Working Time in Canada." Canadian Business Economics, Vol. 2, No. 3, pp.3-16.

Morissette, R. (1998). "The Declining Labour Market Status of Young Men," in Miles Corak ed. Labour Markets, Social Institutions and the Future of Canada's Children, Statistics Canada, Catalogue No. 89-553-XPB, pp. 31-50.

Murphy, Kevin M., W. Craig Riddell and Paul M. Romer (1998). "Wages, Skills and Technology in the United States and Canada." National Bureau of Economic Research Working Paper No. 6638.

OECD (1998). OECD Economic Surveys - Canada, Paris: OECD.

Osberg, Lars, F. Wien and J. Grude (1995). "Vanishing Jobs, Canada's Changing Workplace", James Lorimer \& Company, Toronto.

Picot, Garnett and Zhengxi Lin (1996). "Are Canadians More Likely to Lose Their Jobs in the 1990s?" Analytical Studies Branch Research Paper Series, Statistics Canada, No. 96.

Picot, Garnett (1998). "What is Happening to Earnings Inequality in the 1990s", Canadian Economic Observer, Statistics Canada, Catalogue No. 11-010-XPB.

Picot, Garnett and John Myles (1996). "Low-Income Among Children”, Canadian Public Policy, XXII, No. 3.

Picot, Garnett and John Myles (1998). "Markets Families and Social Transfers", In Labour Market, Social Institution and the Future of Canada's Children, Miles Corak editor, Statistics Canada, Catalogue No. 89-553-XPB.

Picot, Garnett, Zhengxi Lin and Wendy Pyper (1998). "Permanent Lay-Offs in Canada: Overview and Longitudinal Analysis", Canadian Journal of Economics, Vol. 31, No. 5.

Riddell, W. Craig (1995). "Human Capital Formation in Canada: Recent Developments and Policy Responses," in K.G. Banting and C. M. Beach (eds.), Labour Market Polarization and Social Policy Reform, Kingston, School of Policy Studies, Queens University.

Sargent, Timothy C. (1998). “An Updated EI Disincentives Index for Canada," Department of Finance, mimeo, and Human Resources Development Canada.

Sargent, Timothy C. (1999). "Skill Biased Technical Change and the Canadian Economy," Department of Finance, mimeo.

Schuetze, H.J. (1998). "Taxes, Economic Conditions and Recent Trends in Male SelfEmployment: A Canada - U.S. Comparison" McMaster University, Economics Dept., mimeo.

Sunter, Deborah and Geoff Bowlby (1998). "Labour Force Participation in the 1990s", Perspectives on Labour and Income, Statistics Canada, Autumn, Catalogue No. 75-001XPE. 
Wolfson, M. C. and B. B. Murphy (1998). "New Views on Inequality Trends in Canada and the United States." Monthly Labour Review.

Zyblock, Myles (1997). "Why is Family Market Inequality Increasing in Canada?" Human Resources Development Canada, Applied Research Branch Working Paper W-96-11E. 